\title{
A Simplified Model of Nuclear Heating in Tokamaks
}

\author{
C. E. KESSEL. S. L. LIEW, and L. P. KU \\ Princeton Plasma Physics Laboratory \\ P. O. Box 451 \\ Princeton, New Jersey 08543
}

\begin{abstract}
Abtract
The determination of the distribution of heating in fusion devices is impor1:ant for thermo-mechnucal clesign and analysis. The muclear heating is a component of the total heating and is the concern of this paper. For toroidal geometries, such as a tokamak, this is difficult to approximate using simple murels, and typically requires a two-dimensional neutron-gamma transport calculation. The particular problem is to incorporate the poloicial rariation of the heating. A simplified modcl is developed to approximate the nuclear heating as a function of the poloidal angle and depth into the structure of interest. The technique uses ray-tracing and one-dimensional neutrongamma transport calculations. This method has great advantage over the multidimensional neutron-gamma transport calculations, particularly for a frequently changing design. The $1.75 \mathrm{~m}$ Compact Ignition Tukamak (CIT) design is used as an example, and comparisons with two-dimensional results are given.
\end{abstract}
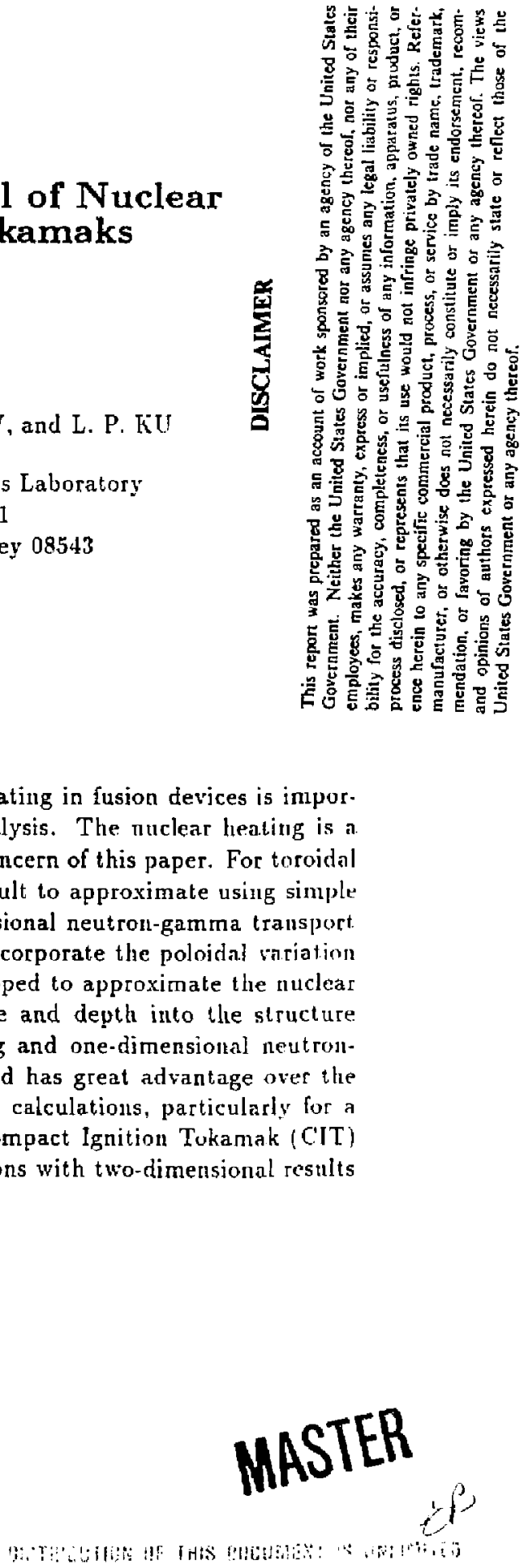


\section{Introduction}

The delermination of the distribution of heating in fusion devices is important for thermo-mechanical design and analysis. Both the absolute temperature and the gradients affect the stresses and relaxation in all structure slurrounding the plasma. Different heating mechanisms can provide varying contributious in different locations. In addition, these contributions are a function of time. The two primary heating mechanisms are resistive and nurcterar, the former being due to $I^{2} R$ losses from electrical currents, atid the latier from neutron and gamma interactions with the material. The primary regions of interest are the structure and the magnets. If the magnets are normal conductors resistive heating will dominate, while superconducting magnets wiil be predoninanty heated by neutrons and gamı rays. J'he structure will typically be heated solely by nuclear processes, except for the lirst wall which will receive a substantial surface heating from plasma particles. In present-day and even next-generation tokamaks. such as the Compact Ignition Tokamak (CIT), the heating will be dominated by the re. sistive component. In the case of CIT the toroidal feld coils also act as a shield. and so although the heating is mostly resistive losses, it provides a good example of a blanket for ane!ysis. However, heat generalion in fusion reactors, with superconducting coils and thick blankets, is likely to be dontinated by nuclear processes. In either case, the nuclear heating distribution must be known to assess the thermal and structural behavior of the device.

For some device geometries, such as a spherical laser fusion chamber or a straiglıt cylindrical mirror reactor, one-dimensional nuclear transport models can be very accurate. However, toroidal geometries, such as a tokamak. are difficult to approximate. The particular problem is to incorporate the poloidal variation of the heating.

There are a uumber of ways to deal with toroidal geometry for the calculation of nuclear heating. On the most detailed level, one may set up thretdimensional deterministir or Monte Carto models for the nention-gamma transport. These are exi uly expensive computationally and ure not considered leasible for global calculations where the fluxes are required at many puints in space. Two-dimensional neutron-gamma transport models can eifortively determine the fluxes over large regions of space, by ignoring some three-dimensional effects, such as those due to ports or limiters. These are still expensive computationally. In addition, the man-hours spent to con- 
strnct the geometric nodel are considerable, particularly for an evolving marhine desiga. One-dimensional models are good for sursey calculativas. but they cannot account for poloidal rariations, which are important in toknmaks. However, these calculations are very rapid, a great number of which can be done in the time it takes for a two-dinensional calculation.

A semi-empirical formula to approximate the heating distribution without lıaving to sun a multidimeusional transport calculatiou, would be quite use ful and coutd be easily updated for a [requentiy changing tokantak design. The purpose of this paper is to arrive at a reasonably accurate expression for the last method. The 1.75 in Cl'T design is used as the example, and the taroidal lield coil heating will be of main concern.

\section{Nuclear Heating Analysis of the Compact Ignition Tokamak}

The Compact Ignilion Tokanak (CIT) is planmed to be a compact, high toroidial held. and high plasma current device that will achieve ignited D. I' plasmas. It will provide the slepping stone to the following gencration w 5 engineering test reactors by providing a study of the physics of ignited plasmas. Some design parameters of this device are listed in Table 1 . It should be emphasized that these do not represent the latest design, which presently las a major radius of $2.1 \mathrm{~m}$.

Shown in Fig. 1 is a cross sectional view of the $1.75 \mathrm{~m}$ CIT design. The first wall is made of carbon tiles nounted on an Inconel 625 vacuum ressel. Outside of this on the upper, lower, and outboard sides is a toroidal field coil suppori made of stainless steel. Outside of this is the set of TF coils, with a slightly different material composition inlword than outbotrd. Surronding this are the poloidal field coils and their support structure, which is surrounded by more structure and a cryostat. A concrete "iglon" then surrounds the entire tokanak to provide a radiation shield.

A I wodimensivinal mude! of this design was cotistructed using the 2.1) discrete ordinates neutron-ganma iransport code. DOT 5.1!1. Since the tokamak is nearly up-down symmetric, it is only necessary to mollet half of the device. This nodel is shown in Fig. 2, which las 21 geometrical: malerial zones. Materials are homogenized using average volume fractions. The grid 
is made up of 166 cadial intervals and 129 vertical intervals. A combination of fully symmetric $S_{8}$ and $S_{+}$angular quadrature sets is used in the angular discretization, and $P_{3}$ Legendre expansions are used for treating the anisotrop! in nuclear cross sections and angular flux. The neutron and gamma cross sections are extracted [rom the VITAMIN-E data set[2]. These are cullapsed iuth the standurd PPPL 2.5 neutron groap and 12 gamma group structure/3i and $|4|$.

ful isotropic volumetric neutron source for the first neutron energ. group (13.5 to $\left.14.9 \mathrm{Me} \mathrm{l}^{\circ}\right)$ is used with the spatial distribution given by

$$
S(R, Z)=S_{0}\left[1-\left(\frac{R-R_{1}}{R_{2}}\right)^{2}\right]^{3}\left[1-\left(\frac{Z-Z_{1}}{Z_{2}}\right)^{2}\right]^{3} .
$$

whete $S_{\sigma}$ is the sinuce nocmalization. In this case $R_{t}=1.55 \mathrm{~m}, R_{2}=11.55 \mathrm{~m}$. aud $Z_{1}$ and $Z_{2}$ are chosen at each $\mathrm{R}$ so that the source is nearly zero at the plasna boundary. which has an elongation of 2.0 and a triangularity of 0.3 .

This 2-D neutron-gamma transport model for the CIT design will be used as the baseline for examining the heating behavior and for comparison with the simplified nodel. The 2-D analysis is itself an approximation, depending '11 the discretization of space, angle, and energy, and does not necessarily represent the actual situation with $100 \%$ accuracy. In addition, it would rerpuire a series of $2-D$ runs with varying discretization to accurately quantify the error: however. this is not considered useful. Thus, it should be kept in mind that the comparisons are only relative.

The neution and gamma fluxes obtained from the 2-D transport calculation are folded witl the kerma factors based on MACKLIB|5] to give the lieating at the inner side of the TF coil. This is shown in Fig. 3, with and withont the first wall and vacumm vessel. The poloidal angle will be defined as $00^{\circ}$ at the outboard and $180^{\circ}$ at the inboard. Clearly, in the presence of the firs wall and ressel the heating is lower; however. the poloidal rariation als, reflects the discontinuities in the ressel geometry. For example, the severe croys in the henting acound $40^{\circ}$ to $50^{\circ}$ is due primarily to the "dog-leg" in the vacunm ressel where the neutrons must travel through a liicker sectirn. At $90^{\circ}$ to $100^{\circ}$ the vessel becomes thicker and another drop in the heating ucruts. althongh this is also due to the distance between the TF cril inner surface and the plasma, since a strong drop also occurs in the no vessel case. At the inboard the heating increnses because the plasma is cluser to the $\mathrm{Tl}$ 
coil there. The turoidal geometry introdices much of the puivilal variaLion. While the plasma and structure shape provide more detailed variotion. Shown in Fig. 4 is a plot of the CIT cross section with chords drawn from the plasma center at various angles. By following the cliords through the first wall and racunn ressel, one catl understand the pulvidal variations in the heating, considering the distance from the plasma to the TF coil inner surface, the thickness of the first wall and vessel, and the angle the cloord pentetrates the first wall and ressel. Although the actual neutron sonrce dues not enanale from the plasma center only, and the heating is not only klue to the incident neutron Hux, this is still useful for interpreting the gross features of the poloidal rariations in the heating. Shown in Fig. 5 is a contour plot of the heating throughout the rcoss section of the CIT device. The materials are all taken as copper siuce the TF coil is ol interest.

To examine the contributions from the gammas, neutrons, and first group ncutrons. to the total heating at the TF coil inner surface, a pint of these is given in Fig. 1;, as a function of polvidal angle. In both cases, witl atul willout the first wall and racum vessel, the gamma contribution dominates. The first group and total neutron contributions show the same shape in both cases. For neutron heating, neutrons in the first group dominate, contributing up to 80 \%or no first wall or ressel. The rest of the neulrons contrilute an almost ronstant hackground. Thus, the poloidal variation in the neition heating is due almost entirely to the variation in the first group neutron Hux. The reduction in the neutron heating with the first wall and vessel is a result of the attenuation in the first group flux by these struclures. The fractions that the gammas and neutrons contribute are different for the two cases. The first wall and vessel basically remove neutrons or scatter them into lower energy gromps where their heating potential is lower. Fewer neutruns rench the TF coil inner surface to produce gammas. This is clear from the shape of the gamna heating curve with the first wall and ressel present. A dip around $411 "$ " $6050^{\circ}$ occurs precisely where the vessel becomes thicker and shunld moce strongly attenuale incident neutrons. This indicates that lhe ganna heating is responding directly to the incident neutrons. It is observed that the gammas produced in the vessel do not appear to contribute much siure they would cause the dip to be less pronounced. The shape of the kanma heating curve without the first wall and vessel is very similar te the first group and total neutron heating, again indicating that it is following the incirlent, neuteon behavior. 
In addition to the poloidal variation in the heating on the $\Gamma F$ coil inner sutface, there is the attenuation of the heating into the TE coil. Shown in Fig. $T$ are two attentuation curves of the heating into the TF coil for polvidal angles of $0^{\circ}$ and $120^{\circ}$. These represent the lieating along a clourd from the plasma center. Included are the gamma and neutron contrihutions to the total heating. The gamma contribution clearly dominates, alt lough near the $\mathrm{TF}$ coil inner surface the neutron contribution is not negligible. Ilowever, deeper into the coil the gamma heating completely determines the total heating. The slopes of the lines are different lor different poloidal angles, however, they are substantially different only around $75^{\circ}$ and $120^{\circ} t 01500^{\circ}$ where the chord along which the attenuation is found does not lie normal to the heating contours. This can be seen in Fig. 5, where healing contunts are included with rhords emanating from the plasma center.

In addition, the neutron and gamma energy spectra can be used t' further unclerstand the contributions and their poloidal distribution. The neutran energy spectrum is shown in Fig. 8a with and without the first wall and ressel at. 11". The only major spectrutn change occurs in the first group, although an increase in the fiftl group flux ( 9.2 to $10.0 \mathrm{MeV})$ due to inelastic scatlering in the graphite first wall can be seen, the remaining spectrum is fairly well prescrved. This has been olserved to be trne of all angles, and indicates the drop in the neutron heating is mainly due to the drop in the first group neulcon flux. Figure $8 \mathrm{~b}$ shows the gamma spectrum at $0^{\circ}$ and shows blat the spectrum shape is preserved, but there is an overall drop in the gamma flux, ceflective of the drop in the first group neutron flux.

As a comparison to the 2.D results and to illustrate a "typical" onedimensional analysis of the problem, ANISN|6! was run with vertical cylinder geometry, w'.ere the axis of symmetry was coincident with the marhine renterline. The material/zone and source information from the tirst vertical interval of the 2-D problem was used. A volumetric source was used with normalization corsesponding to the equivalent of $300 \mathrm{NIW}$ of total fusion power and a vertical plasma lucight of $2.2 \mathrm{~m}$. Shown in Fig. 9 is the healing along the major radius coordinate. All materials are treated ns copper. The lieating of the TF coil inner surface for the outboard is $310.3 \mathrm{~W}$; cre and for the inboard is $10.1 \mathrm{~W} / \mathrm{cc}$. Hese compare quite well with the $11^{\prime \prime}$ hol $180 "$ $2-1)$ results of $27.4 \mathrm{~W} / \mathrm{cc}$ and $+\mathrm{l} . \mathrm{l} \mathrm{W} / \mathrm{cc}$. However, to use an nverage hent. ing value of 35.2 W/cc would severely overestimate the entire outborarl and especially around $90^{\circ}$ to $120^{\circ}$. Another possible averaging method weinlat lie 
to use $30.3 \mathrm{~W}^{\circ}$ ce from $0^{\circ}$ to $90^{\circ}$ and $40.1 \mathrm{~W} / \mathrm{cc}$ from $91^{\circ}$ to $180^{\circ}$. These are shown superimposed in Fig. 3. Neither would represett the peloidial variation of the heating even in an average sense. Both methods have a ront mean square deviation and percent deviation of $10 \mathrm{~W} / \mathrm{cc}$ and $54 \%$, respectively.

The 1-D transport calculation treats the plasma neutron source as infinite in the Z direction. the dividing of the plasma source lyy the plasma height is tor compensate for this. However, the region of the tokamak above the plasma is seglected in these calculations and cannot be re-introduced. Only the l/ $R$ clfect of the toroidal geometry is represented, but there is artually additional dirergence. Introducing poloidal variation is iot possible and this is the main drawback of using 1-D transport calculations only. One-dimensional models nould be useful if only an average heating was required say for bulk power balance: however, we are interested in the poloidal variation of the heating, which requires more information than can be provided by 1-D analysis.

\section{Simplified Model and Computational Pro- cedure}

The leating is deternined by folding the neutron and gamma group lluxes with energy-dependent kerma factors. The neutron-ganma transport and scattering, as well as the energy structure of the kerma factors makes an nnalysis of the contributions of heating terms very complicated. Eren to exanine heating from gammas and neutrons separately is involved because the gammas dominate the lieating, yet they are produced by scattering and absorption of neutrons of all energies. This does not allow them to be casily correlated to the source of neutrons. Observations in the previous section led us to believe that the poloidal variation in the heating could be accotuted for by treating it as a sum of two contributions; a iocal or primary and a distant or secondary. Each of these is composed of both tueutron and gamma parts that will not be resclved. The primary term acconnts for the direct healing elfects of neutrons incident locally and the secondary lerm represents the effects of neutrons incident on all other regions. Attached to this is an exponential decay term to accunt for the drop of the heating into the t'F criil. 
llence. the leating at a given poluidal angle $\theta$ is represented by

$$
H(x, \theta)=\left(H_{1}(\theta)+H_{2}(\theta)\right) e^{-\frac{\theta}{4}},
$$

where $H_{1}$ is the primary and $H_{2}$ is the secondary heaing terms, $\lambda$ is the attenuation length for the heating, and $x$ is the coordinate along a chord front the plasma center at $\theta$ into the coil $(x=0$ is at the coil inner sucface). $\lambda i^{\prime}$ f first approximation we have assumed that $\lambda$ is inclependent of $\theta$. One way of expressing $H_{1}$ and $H_{2}$ explicitly is,

$$
H(x, \theta)=\left[C_{1}(\theta), I(\theta)+\int_{\theta^{\prime} \neq \theta^{\prime}} C_{2}\left(\theta, \theta^{\prime}\right) J\left(\theta^{\prime}\right) d \theta^{\prime}\right] \mathrm{e}^{-\frac{\pi}{2}},
$$

where $C_{\mathrm{t}}(\theta)$ is the heating rate at the TF coil inner sarface per unit incident $14 \mathrm{NCl}$ neutron current at $\theta$. and $C_{2}\left(\theta, \theta^{\prime}\right)$ is the heating rate at $\theta$ per unit incident $1+\mathrm{MeV}$ current at $\theta^{\prime}$. per unit angle. $J(\theta)$ is the incident 1 . MeV nettron current at the TF coil surface. and the integral is over all poloidal angles not equal to $\theta$. The neutron current can be expressed as $J(\theta) \equiv J f(\theta)$. where $J$ is the average current en the TF coil surface, and $f(\theta)$ is the angular ncutcon current distribution nomalized to the average. Approximating the integral by a sum gives.

$$
H(x, \theta)=\left[C_{1}(\theta) f(\theta)+\sum_{x=1, \theta_{i}^{\prime} \neq \theta}^{N_{\theta}} C_{2}\left(\theta, \theta_{i}^{\prime}\right) f\left(\theta_{i}^{r}\right)\right] \bar{J}_{e^{-\frac{\pi}{\lambda}}}
$$

$C_{2}\left(\theta, \theta^{\prime}\right)$ is defined here to be the heating rate at $\theta$ per unit incident $14 \mathrm{MleV}$ current at $\theta^{\prime}$, the angular increment being absorbed. At this point there are a unuber of possible further reductions. The present form with the sun uver a large number of angles is still very difficult to evaluate. In order that $C^{\prime}$, and $C_{z}$ can be evaluated $u \cdot j t h$ simple 1.D transport models. the expression is simplified into two terms, primarily because the 1-D transport analysis call provide unly two heating values, one at $10^{\circ}$ and one at $180^{\circ}$. This remuv's the $\theta$ dependence from the heating terms $C_{1}$ and $C_{2}$ and makes them strictly ourhoard and inboard terms. The $f(\theta)$ then provides the only poloidai variation, $90^{\circ}$ is arlitracily chusen as the dividiug liue betueen the inbuard and outhoard. For angles between $0^{\circ}$ and $90^{\circ}$ the primary heating term is $C_{1}(\theta)=C_{1}\left(0^{\circ}\right)$ and the secondary term is $C_{2}\left(\theta, \theta^{\circ}\right)=C_{2}\left(10^{\circ}, 180^{\circ}\right)$. For antgles hetween $91^{\circ}$ and $180^{\circ}$ the primary heating term is $\left.C_{\mathrm{L}}(\theta)=C_{1}(181) "\right)$ 
and the secondary term would be $C_{2}\left(\theta, \theta^{\prime}\right)=C_{2}\left(180^{\circ}, 0^{\circ}\right)$. With respect to the I-D transport geometry, the priniary heating for the outboard angles is considered due to a source emanating from the outboard side of the plasma. all neutions launched to the right. The secondary heating for the outboard angles is due to a source emanating from the inboard side of the plasma and being scattered back to the outboard side, all neutrons launched to the left. The converse is true for the inboard heating. This is illustrated in Fig. 10. The heating breaks up into two expressions, one for outboard and one for inbward.

$$
\begin{aligned}
& H\left(x, 11^{\circ} \leq \theta \leq 91^{\circ}\right)=\left[C_{1}\left(10^{\circ}\right) f(\theta)+C_{2}\left(0^{\circ}, 180^{\circ}\right) f\left(180^{\circ}\right)\right] \cdot J^{-\frac{\sigma}{2}} \\
& H\left(x .91^{\circ} \leq \theta \leq 180^{\circ}\right)=\left[C_{1}\left(180^{\circ}\right) f(\theta)+C_{2}\left(180^{\circ}, 0^{\circ}\right) f\left(0^{\circ}\right)\right] J e^{-\frac{\sigma}{\lambda}}
\end{aligned}
$$

However, the secondary heating terms are due to scattered neutrons and ganimas from one side of the tokamak to the other and have essentially lost menory of theic source, while $f(\theta)$ represents the poloidal variation of the It MeV incident neutron current. Thus, the secondary term should not be related to the incjdent neutrons, but rather treated as a constant background. The alonve expressions then reduce to,

$$
\begin{gathered}
H\left(x, 0^{\circ} \leq \theta \leq 90^{\circ}\right)=\left[C_{1}\left(0^{\circ}\right) f(\theta)+C_{2}\left(0^{\circ}, 180^{\circ}\right)\right] \cdot J^{-\frac{x}{\lambda}} \\
H\left(x, 91^{\circ} \leq \theta \leq 180^{\circ}\right)=\left[C_{1}\left(180^{\circ}\right) f(\theta)+C_{2}\left(180^{\circ}, 0^{\circ}\right)\right] J^{-\frac{\varepsilon}{\lambda}}
\end{gathered}
$$

As slown in the following sections, $f(\theta)$ and $\bar{J}$ will be obtained from a raytracing procedure, and $C_{1}, C_{2}$, and $\lambda$ will be evaluated using $1-D$ transport morlets.

\subsection{Toroidal Geometry Ray-Tracing}

The poloidal yariation of neutron current $f(\theta)$ can be obtained from simple ray-tracing calculations $[\bar{i} \mid$ and $[8]$. The ray-tracing calculation only treats the ueutron streaming problem for the $14 \mathrm{MleV}$ neutrons. Given a specilied ncutrou source distribution within the plasma, the algorithm determines the angular fluxes. $F(x, \phi)(x$ and $\phi$ are the angles in a spherical coordinate system at a point) and $F(x)$, and the scalar flux $F$ and current J, at various potciclal angles $\theta$ on a specified surface. The geonetry is illustrnted in ligg. 11. These quantitjes are otly for the $14 \mathrm{MeV}$ uncollided neutrous, so the 
first $w$ all and yacuum vessel are neglected. In addition, an average neutron wall loading $J$ is calculated as the ratio of the total nention power to the surface area. Since the ray-tracing is three-dimensional the artual toroidal geometry can be accounted for. The ray-tracing calculation is done for the plasma surface and again for the TF coil inner surface, with the neutron source distribution within the plasma given by

$$
S(R, Z)=S_{o}\left[1-\left[\frac{\left(R-R_{o}\right)^{2}}{a^{2}}+\frac{Z^{2}}{\kappa^{2} a^{2}}\right]\right]^{3}
$$

where $R_{0}, a$, and $\kappa$ are the plasma major radius, minor radius, and elongation, respectively. $(R, Z)$ is the position inside the plasma. The source specification used in the 2-D transport model is slightly different[1], however the difference is in the fourth order and is found to be negligible. The scalar nentron current at the TF coil inner surface is represented as $J(\theta) \equiv \bar{J} f(\theta)$, aud the $f(\theta)$ term is used to weight the primary leating term. This is based on two prennises; that the poloidal variation of the heating will have similar shape to the $14 \mathrm{MeV}$ uncollided neutron current, and that the poloidal variation of the neutron current will not change siguificantly with first wall aurd vessel present. However the varjation is not as sharp for the heating as it is for the neutron current, so the secondary term is required to reduce the degree of variation. The plasma ray-tracing results are used in the $1-D$ analysis discussed in the next section.

\subsection{One-Dimensional Transport Models}

Three one-dimensional geometries are available; slab, sphere, and cylinder. The neutron source ran be specified as a volunie or shell source, although only the sliell source can accommodate an anisotropic angular distribution. The slab and vertical cylinder models have infinite exient vertically. These calculations deternine the neutcon and gamma fluxes along one coordinate, with which the kerma factors can be folded to calculate heating or any other response. Thus, the spatial dependence of the fluxes, currents, and heatjng are available; however, only the $0^{\circ}$ and $180^{\circ}$ from the 2-D morlel can he simulated.

Since the ray-lracing provides the angular neutron flux $F(x)$ as a function of angle $x$ (or $\mu=\cos \gamma$ ), for various poloidal angles, this can be used in $n$ 
shell source for L-D transport. The angular neutron source distribution at the plasma surface from the ray-tracing at $0^{\circ}$ is then used in a stiell source at the outboard plasma edge of a 1-D transfort calculation. The resulting heating on the outboard is the outboard primary heating $\left[C_{1}\left(0^{\circ}\right)\right]$ and the heating on the inboard is the inboard secondary heating $\left[\hat{O}_{2}\left(180^{\circ}, e^{\circ}\right)\right]$. This is repeated with the $180^{\circ}$ angular neutron source distribution used in a shell source at the inboard plasma edge. The inboard heating is the inboard primary $\left[C_{1}\left(180^{\circ}\right)\right]$ and the outboard heating is the outboard secondary $\left[C_{2}\left(0^{\circ}, 180^{\circ}\right)\right]_{\text {. Th }}^{i}$ This schematically illustrated in Fig. 10. This only provides two different total thealing values. The $1-D$ transport caiculations are done with $1 \mathrm{MW} / \mathrm{m}^{2}$ current shell sources at ti.e plas za, so the heating at the $T$ coil is per unit current at the plasma surface. In addition, the ray-tracing gives the average neutron wall loading at the plasmb surface. The correlation requires these quantilies to be per unit current at the $T F$ coil, and the average wall loading on the TF coil, respectively, so they must be renormalized. The renormalizing factor is taken from the drop in the first group current from the plasma surface to the TF coil calculated from a slab 1-D transport nudet.

The $1-\mathrm{D}$ analysis also gives the heating spatially into the TF coil at $0^{\nu}$ and $180^{\circ}$. The slope of the decay in the heating is the attenuation lengin $\lambda$, used in the correlations. An average is taken between the inboard and uutbuard vilues, althought they could be used separately since the correlations are separate.

\section{Results}

The model views the healing as due to a local and a distant source. Due to the limitations of 1.D transport, only the $0^{\circ}$ and $180^{\circ}$ from the 2.D analysis can be simulated, so that the local and distant heating terms are derived for these poloida! angles only. In effect, the primary heating lem is correlated to the incident $14 \mathrm{MeV}$ neutron current. and so the poloidal variation factor $(f(\theta))$. from the ray-tracing, is attached to this term. The secondary heating has lost memory of :ts source and so it is represented as a constant background added on. This justification is not wirhout meril. However. the complicated energy structure of the Huxes and kerma factors coupled with the geometry of the lokamak make its proof from first princjples inpossible. 
The heating is dominated by gammas, not the 1.4 MeV ueutrous, and the anmmas are not produced only by the 1 I MeV nentrons. Thus, at first glance there appriars to be ne reason why the polejithl henting vnrinticu should follow the distribution of the $14 \mathrm{MeV}$ neutrons. However, they do show similar behavior, iljustrated in Fig. 3, where without the first wall and ressel the shapes of the gamma heating and $14 \mathrm{MeV}$ nentron heating. are quite similar. When the first wall and vessel are included, the gamma lieating reflects the discontinuities in these structures more than the $14 \mathrm{MeV}$ neutrons. Fron the neutron spectrum results, the first wall and vessel mainly renuve $14 \mathrm{MeV}$ neutrons while leaving the remaining spectrum unchanged. This would infer that the drop in the total and gamma heating is, in fact, due mainly to the drop in the $14 \mathrm{MeV}$ neutron flux reaching the TF coil inner surface. This would be a critical function of the first wall and vessel il:ickness, since as it got thicker it would begin to inlluence other groups more strongly.

The simplified model is based on trends from the 2-D transport analysis, as well as the available calculations that can be made withont actually doing a 2-D calculation.

Shown in Fig. 12 are the $14 \mathrm{MeV}$ scalar flux and current from the raytracing calculation as a function of poloidal angle for $300 \mathrm{MW}$ total fusion prower for the CIT geonetry. These are for both the plasma surface and at, the TF coil inner surface. The fux and current at the TF coil is lower than that at the plasma surface due to geometrical divergence, and the outboard values drop much faster than the inboard since the distance to the $T F$ coil is larger on the outboard. The curves stress the fact that the flux and current distributions are strongly dependent on the surface chosen.

In addition to the scalar flux and current, the angular fluxes are avail. able. The particular angular fuxes, $F(\chi)$ [or $F(\mu), \alpha=\cos x$ ], at the plasnia surface for $0^{n}$ and $180^{\circ}$ are used in the shell source 1-D transport to determine the heating and attenuation. Shown in Fig. 13 are these distributions for the inboard and outboard, at the plasma surface and the $T F$ coil inner surface. These show that the neutron angular source distributions are quite different from inboard to outboard. being heavily peaked to ward normal on the uutboard. Also, neither distribution would be well approximated by a Rat distribution. It should be emphasized that these are neutonl streaming calculations and cannot treat material between the neutron source and the surface of inlerest. 
The one-dimensional transport was $u^{\prime}$ d with a slab, sphere, and verticul cytinder, using the hist vertical interval foum the 2-D nodel for the mutcriat and zone information. This muterial description is shown in Fig. 1.1. Slown in Fig. 15a and b are the heating profiles across the tokumak trom the 1-D analysis. For outboard and inbourd shell sources, respectively. These are for cylitrical geometry, and assume the materials are all copper, sinct the TF coil is of prinary interest. The values for the primary and secondary heating per unit current at the plasma surface for all three geometries are gives it Table 2, with the renotmalized values in parentheses.

Graphs of the nuclear heating rates at the TF coil inner surface from the curelations versus the 2-D results are shown in Fig. I6a and h, the former with the first wall and yessej and the latter without. All three $\mathrm{L}-\mathrm{D}$ geometries are shown. The agreement is reasonable considering the simple form of the expression and the complicated quantity being estimated.

"'he curves for the case with first wall and vessel overestimate near $41^{\circ}$, $90^{\circ}$. and between $140^{\circ}$ and $180^{\circ}$. At $40^{\circ}$ and $90^{\circ}$ the vacuum vessel is lihirlier than at $v^{\circ}$, which the correlation is based on, lending to the drop in the heating there. The overestimate at the inboard is more complicaled and is likely due to the limitalions of the $1-D$ modelling, particularly too large a value for the inboard secondary heating. The "wiggle" in the two correlation curves around $90^{\circ}$ is due to the switchover from the ontboard correlation to the inboard one. The average deviations for no first wall or vessed are $7,4 \%$ for spherical, $7.1 \%$ for cylindrical, and $9.3 \%$ for slab. With the first wall and sessel included the average deviations are $12.6 \%$ for spherical, $18.8 \%$ for rylindrical, and $15.6 \%$ for slab. The average deviation is defined as the sum of the absolute values of the differences between the heating value calculated with a 2-D transport model and the predicted value from the correlation. sormalized to the $2-D$ value. The entire sum is then normalized by the number of points used for comparison. It should be emphasized that the :-1, model is also approximate, so the deviations are relative.

$$
\text { alerage deviation }=\frac{1}{N} \sum_{i=1}^{N}\left(\frac{\mid H_{2-D}-[H(x . \theta) \mid}{H_{2-D}}\right)
$$

These are reasunable error syreads considering the simplicity of the morld.

Shown in Fig. 17 is heating as a function of depth into the $\mathrm{TF}$, il for a few polvidal angles. The disferences in the slopes at varives angles nre due 4 ." 
the geometry of the TF coil compared to the chord drawn from the plasma center through the coil at a given angle. This is illustrated in Fig. T where lierting contours ace shown with the same chords included. At IE10 the chord does not cross the heatiug contour at a right angle and so a different decay rate than at $\mathbf{v}^{\circ}$ where the chord is normal is present. If the ' $\mathrm{I} \mathrm{F}^{\prime}$ coil were circular, the chords would all cross the contours at $90^{\circ}$ angles. The I-D transport can only give two values for the attenuation length, at $0^{\circ}$ and $180^{\circ}$. Since the coil geometry can be-complicated, an average between the two values is used as a constant $\lambda$ for all poloidal angles with the present model. Greater effort can be made to make $\lambda$ a function of $\theta$ by examining the structure geometry. There can be considerable disagreement, particularly near the top of the TF coil.

\section{Conclusions}

The actual neutron-gamma transport problem in two or thee dimensions is quite complicated and it is impossible to reproduce the same environment with 1-D models for toroidal geometry. The multi-energy group scoltering anakes it possible only to approximate heating values to within some chegree of error. In fact, the only reason one may get close values wit ly a simplificd model is because tile response is a sum over all energy groups, causing fine scale differences between the true system and the simplified model to be smeared out.

A simplified model for approximating the nuclear heating in structure of magnets for toroidal geometries lias been developed that can circumvent the need for a multidimensional neutron-gamma transport calculation. This is particularly useful for evolving machine designs where the frequent updating of a rigorous multidimensional model would be very time-consuning. The average deviations, in the example of CIT at the inner side of the TF coil. are alıout $i-10 \%$ without the vacuum vessel and $12.18 \%$ with the ressel included. The model relies on tay-tracing and 1-D veutron-gamma transport calculations. The computational times for these are considerably less than a 2-D calculation (typically $5 \%$ ).

This method call allow for different neutron source proftles in the plasma that. caunot be adequately represented in 1-D transport calculations alone.

The presesti nodel is based on three primary assumptions: the pulquidal 
variation in the heating can be related to the poloidal variation in the incident I.t MeV neutron cutrent, that the poloidal variation of this curcent will not be significantly altered npon passing thruugh the first wall ast vacnum vessel. and the decay of heating into the coil can be described by a single attenuation length.

The first two assumptions can be violated when the structures between lhe plasma and the region of interest becone very thick or highly nonmiform. These would strongly affect the $14 \mathrm{MeV}$ neutron current and the ray-iracing would be unable to account for this. The error introduced by using in single attenuation length is not very significant in CIT since the heating value already drops by more than an order of magnitude when the error becomes large. However, it is significant for superconducting coils shielded by a blanket/shield structure. The error introduced can be more than a factor of 2.

The choice of $90^{\circ}$ as the switchover point for using the outboard to inboard corrclation is arbitrary, and this can be used as an adjustabic parameter depending on the structure geometry, material composition, or any other change that could create a different heating rate.

The model may be generalized to include other responses with appropriate clanges in the parameters. Physical insight into a particular application may improve the errelation of offer a better form than the one presented here for heating. 


\section{References}

[1] S. L. Liew, L. P. Ku, and C. E. Kessel, "Two-Dimensional Discrete Ordinates Calculations of Prompt Railintion Respunses in the $1.75 \mathrm{~m}$ CIT," Proc. $8^{\text {th }}$ Top. Meeting on Tech. Fusion Energy, Salt Lake City, Oct. 1988; to be published in Fusion Technology.

[2] R. W. Roussu et al., "VITAMIN-E: A Coupled 174 Nentron 38 GammaRay Multigroup Cross-Section Library for Deriving Applications Dependent Working Libraries for Radiation Transport Calculations," RSIC Report DLC.113, Oak Ridge National Laboratory, Nov. 198T.

(3) L. P. Ku and J. Kolibal, "XCNVRT: A Multigroup Cross-Section Collapsing Code, A User's Guide," EAD-R-7, Princeton Plasina Physics Lab'satury Technical Meno, 1982.

(1) L. P. Ku and J. Kolibal, "PRAX-C: PPL Radiation Analysis CrossSections for the Cray," EAD-R-1, Princeton Plasma Physics Laboratory Technical Memo, 1982.

(5) Y. Gollar and M. A. Abdou, "MACKLIB-IV, A Library of Nuclear Response Functions Generated with the MACK-IV Computer Program from ENDF/B-IV," ANL/FPP/TM-106, March 1978.

[6] L. P. Ku and J. Koljbal, "ANISN/PPL-C: A One-Dimensional Multigroup Discrete Ordinates Code, A User's Guide for the Cray," EAD-R11, Princeton Plasma Physics Laboratory Technical Memo, 1982.

(7) W. G. Price, Jr. and D. L. Chapin, "Neutron Wall Load Distributions in a Circular Cross-Section Tokamak," MATT-1102, Princetou Plasma Physics Lab., 1975.

(8) D. L. Chapin and W. G. Price, Jr., "A Comparison of the DcuteriumTritium Neutron Wall Load Distributions in Several Tokamak Fusion Reactors," Nucl. Techuol., 31, Oct. 1976. 


\begin{tabular}{|l|l|}
\hline Major Radius & $1.7 \mathrm{~s} \mathrm{~m}$ \\
Minor Plasma Radius & $0.55 \mathrm{~m}$ \\
Plastna Elongation & 2.0 \\
Plasma Current & $9 \mathrm{ML}$ \\
Toroidal Field (baseline) & $10.0 \mathrm{~T}$ \\
Plasma Burn Time (up to) & $5.0 \mathrm{~s}$ \\
Neutron Wall Loading (at $300 \mathrm{MW}$ ) & $4.2 \mathrm{MW} / \mathrm{m}^{2}$ \\
Peak Power for TF and PF Coils & $1.1 \mathrm{TW}$ \\
Number of Full-Field Puises & 3000 \\
\hline
\end{tabular}

Table 1. Selected paraneters of the 1.75 m baseline CIT design. 


\begin{tabular}{|c|c|c|c|}
\hline Slab & outboard & $\begin{array}{l}C_{1}\left(0^{\circ}\right)=5.45 \mathrm{~J} / \mathrm{kg} \\
C_{2}\left(0^{\prime \prime}, 180^{\circ}\right)=153 \mathrm{~J} / \mathrm{kg} \\
C_{1}\left(180^{\circ}\right)=66.4 \mathrm{~J} / \mathrm{kg} \\
C_{2}\left(180^{\circ}, 0^{\circ}\right)=220 \mathrm{~J} / \mathrm{kg}\end{array}$ & $\begin{array}{l}(2127 \mathrm{~J} / \mathrm{kg}) \\
(615 \mathrm{~J} / \mathrm{kg}) \\
(2668 \mathrm{~J} / \mathrm{kg}) \\
(859 \mathrm{~J} / \mathrm{kg})\end{array}$ \\
\hline Sphere & $\begin{array}{l}\text { outboard } \\
\text { inboard }\end{array}$ & $\begin{array}{l}C_{1}\left(0^{\circ}\right)=467 \mathrm{~J} / \mathrm{kg} \\
C_{2}\left(0^{\circ}, 180^{\circ}\right)=53.6 \mathrm{~J} / \mathrm{kg} \\
C_{1}\left(180^{\circ}\right)=655 \mathrm{~J} / \mathrm{kg} \\
C_{2}\left(180^{\circ}, 0^{\circ}\right)=262 \mathrm{~J} / \mathrm{kg}\end{array}$ & $\begin{array}{l}(2230 \mathrm{~J} / \mathrm{kg}) \\
(198 \mathrm{~J} / \mathrm{kg}) \\
(2422 \mathrm{~J} / \mathrm{kg}) \\
(1251 \mathrm{~J} / \mathrm{kg})\end{array}$ \\
\hline Cylinder & outboard & $\begin{array}{l}C_{1}\left(0^{\circ}\right)=519 \mathrm{~J} / \mathrm{kg} \\
C_{2}\left(0^{\circ}, 180^{\circ}\right)=100 \mathrm{~J} / \mathrm{kg} \\
C_{1}\left(180^{\circ}\right)=637 \mathrm{~J} / \mathrm{kg} \\
C_{2}\left(180^{\circ}, 0^{\circ}\right)=257 \mathrm{~J} / \mathrm{kg}\end{array}$ & $\begin{array}{l}(2269 \mathrm{~J} / \mathrm{kg}) \\
(4 \mathrm{~J} 1 \mathrm{~J} / \mathrm{kg}) \\
(2745 \mathrm{~J} / \mathrm{kg}) \\
(1123 \mathrm{~J} / \mathrm{kg}) \\
\end{array}$ \\
\hline
\end{tabular}

Table 2. Primary and secotidary heating for all three $1-D$ geometries 


\section{List of Figures}

FIGURE 1. Cross-sectional view of the $1.75 \mathrm{~m}$ CIT design

FIGURE 2. Geometry/malerial definition for the model used in the twodimensional transport calculation. Regions have been shaded to dis. tinguish zones.

FIGURE 3. Poloidal distribution of the heating on the inner side of the TF coil, with the first wall and vacuum vessel (a), and without (b).

FIGURE 4. Cross-sectional view of the two-dimensional CIT model with chords drawn from the plasma center at various angles.

FIGURE 5. Contour plot of the heating throughout the cross section of the CIT morlel with chords drawn from the plasma center at various angles.

FIGURE 6. Poloidal distribution of the leating on the inner side of the TF coil, with the total, total gamma, total neutron, and first group neutron contributions, with the first wall and vacuum vessel (a), and williout (b).

FIGURE 7. Attenuation of heating into the TF coil, at $0^{\circ}$ (a) and $120^{\circ}$ (b). including gamma and neutron contributions.

FIGURE 8. The energy spectra with and without the fist wall and vacuum vessel for neutrons (a) and gammas (b).

FIGURE 9. Heating along the major radjus coordinate for $1-D$ transport calculation.

FIGURE 10. Illustration of the primary and secondary heating for the $I-D$ transport geometry.

FIGURE 11. The coordinate system used in the ray-tracing calculation.

FIGURE 12. $14 \mathrm{MeV}$ scalar flux and current as a function of poletidal angle for $300 \mathrm{MW}$ total fusion power for CIT. 
FIGURE 13. The angular flux $F(x)$ at the plasma surface and $T F$ coil inner surface at $0^{\circ}$ and $180^{\circ}$.

FIGURE 14. Material description for the 1-D transport model. item FlG. UlXE 15. Heating profiles along the major radius coordinate for the A.D calculation for outbuard (a) and inboard (b) shell sources.

FIGURE 16. Poloidal distribution of the heating ca the inner side of the $T F$ coil from the 2-D analysis and the correlation, with the first wall and vacuum vessel (a), and without (b).

FIGURE 1i. Attenuation of the heating into the TF coil for a few poloidal angles compared with the correlation. 


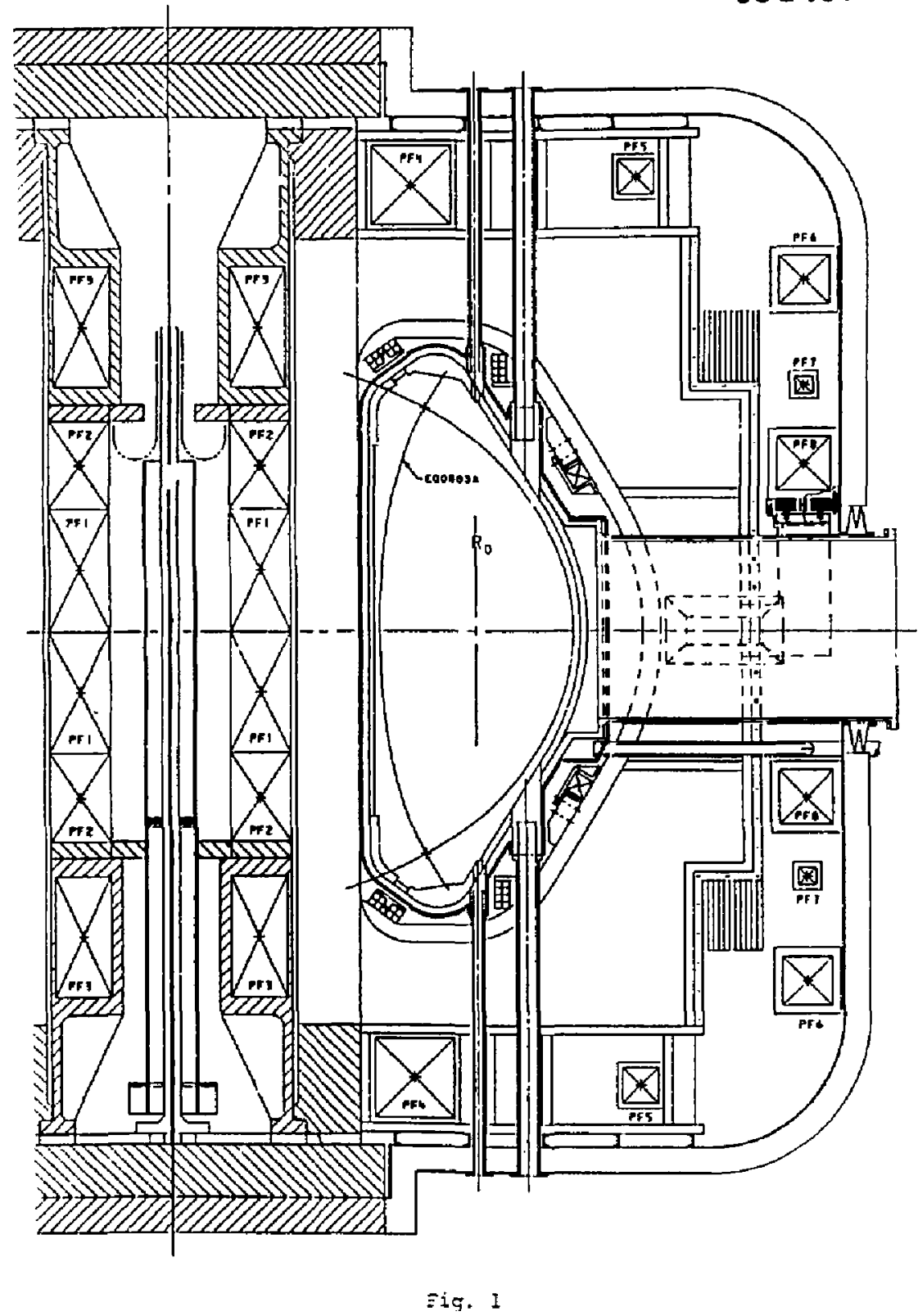




\section{R.Z GEOMETAY OF THE TWO-DIMENSIONAL MODEL}

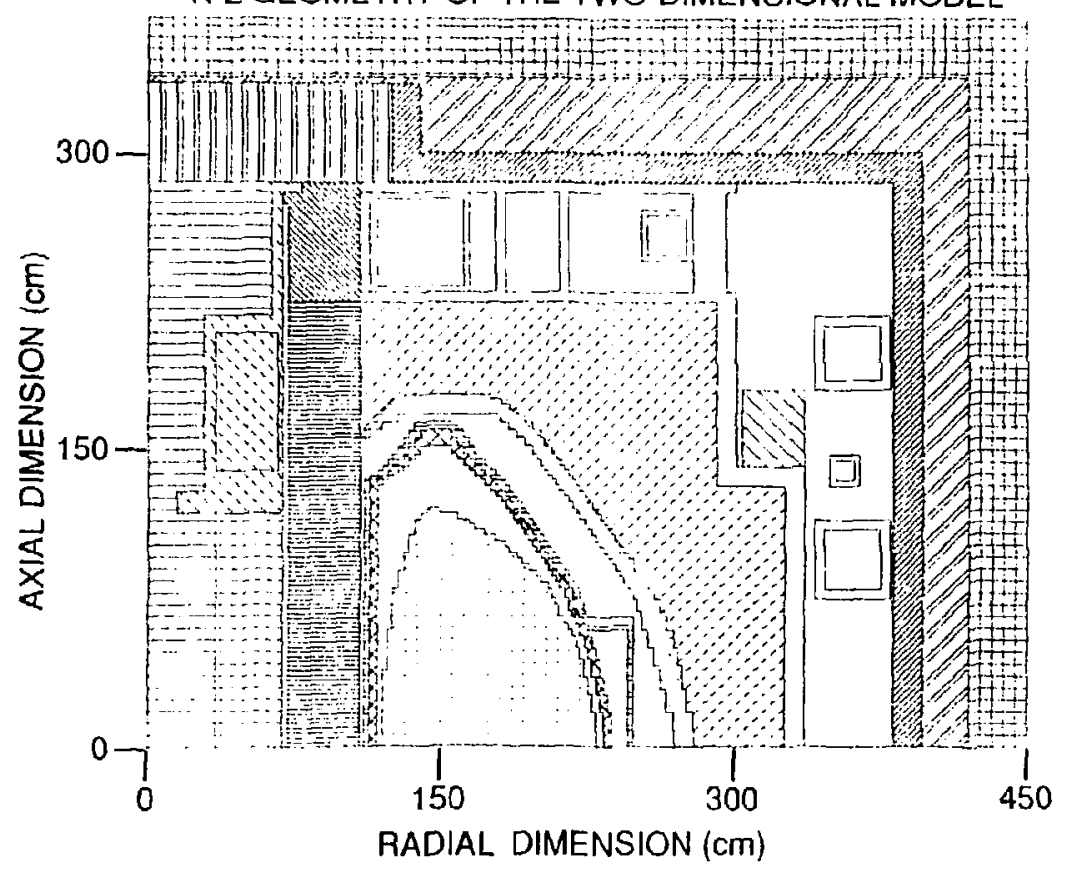

Fili. ? 


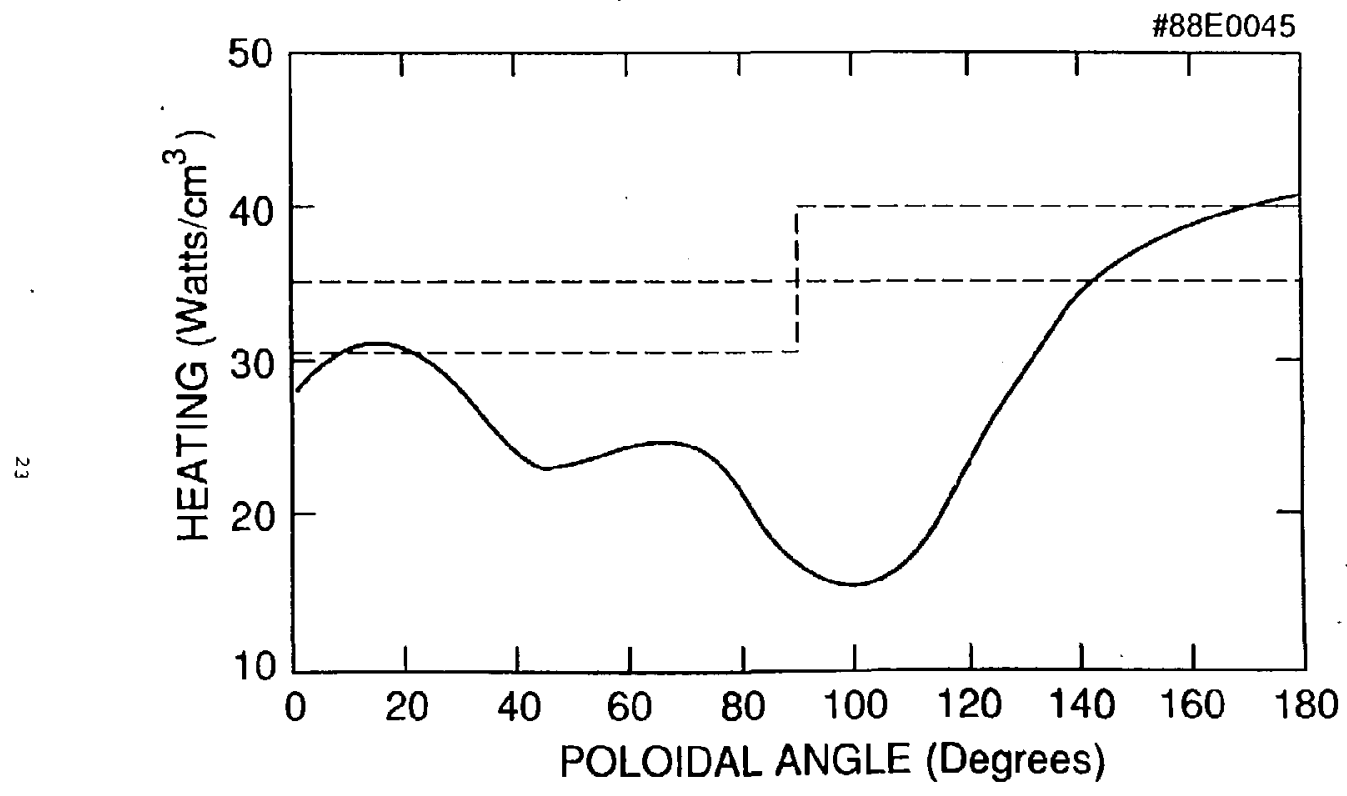




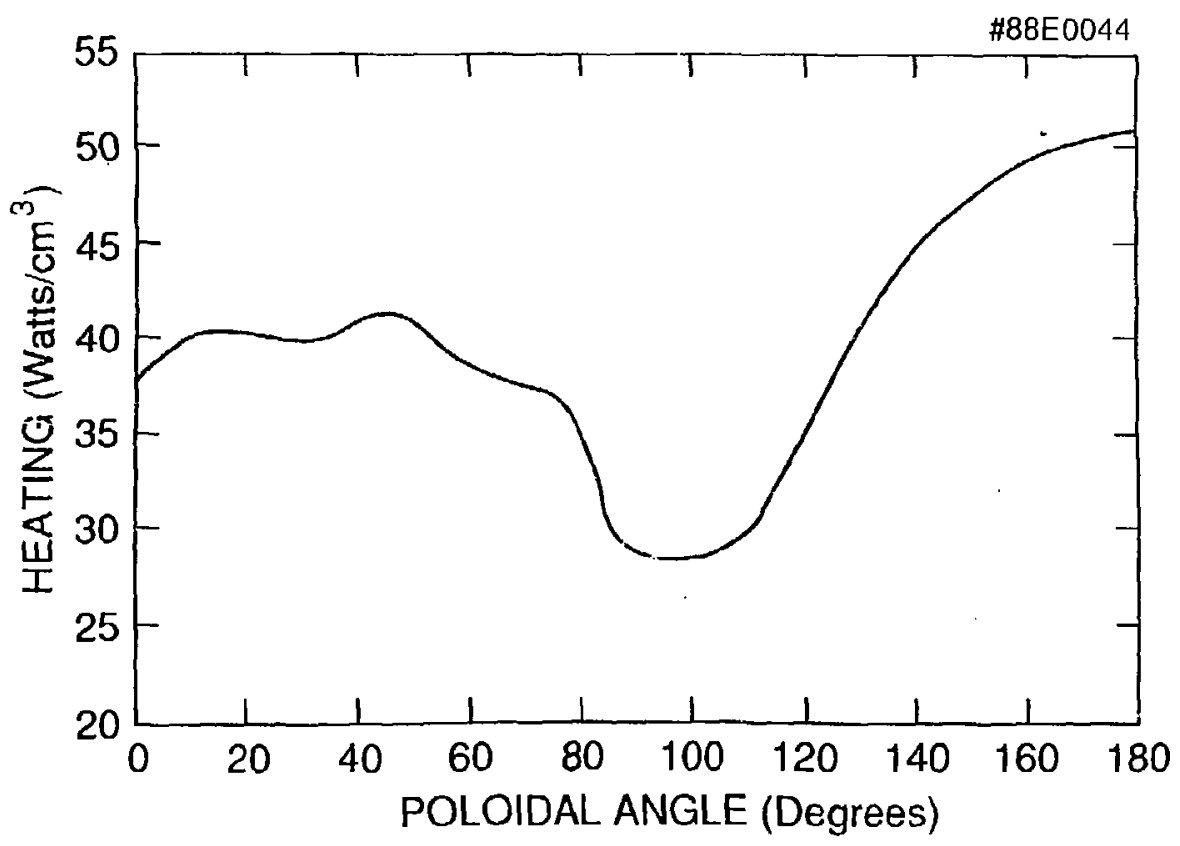




\section{AXIAL DIMENSION (m)}

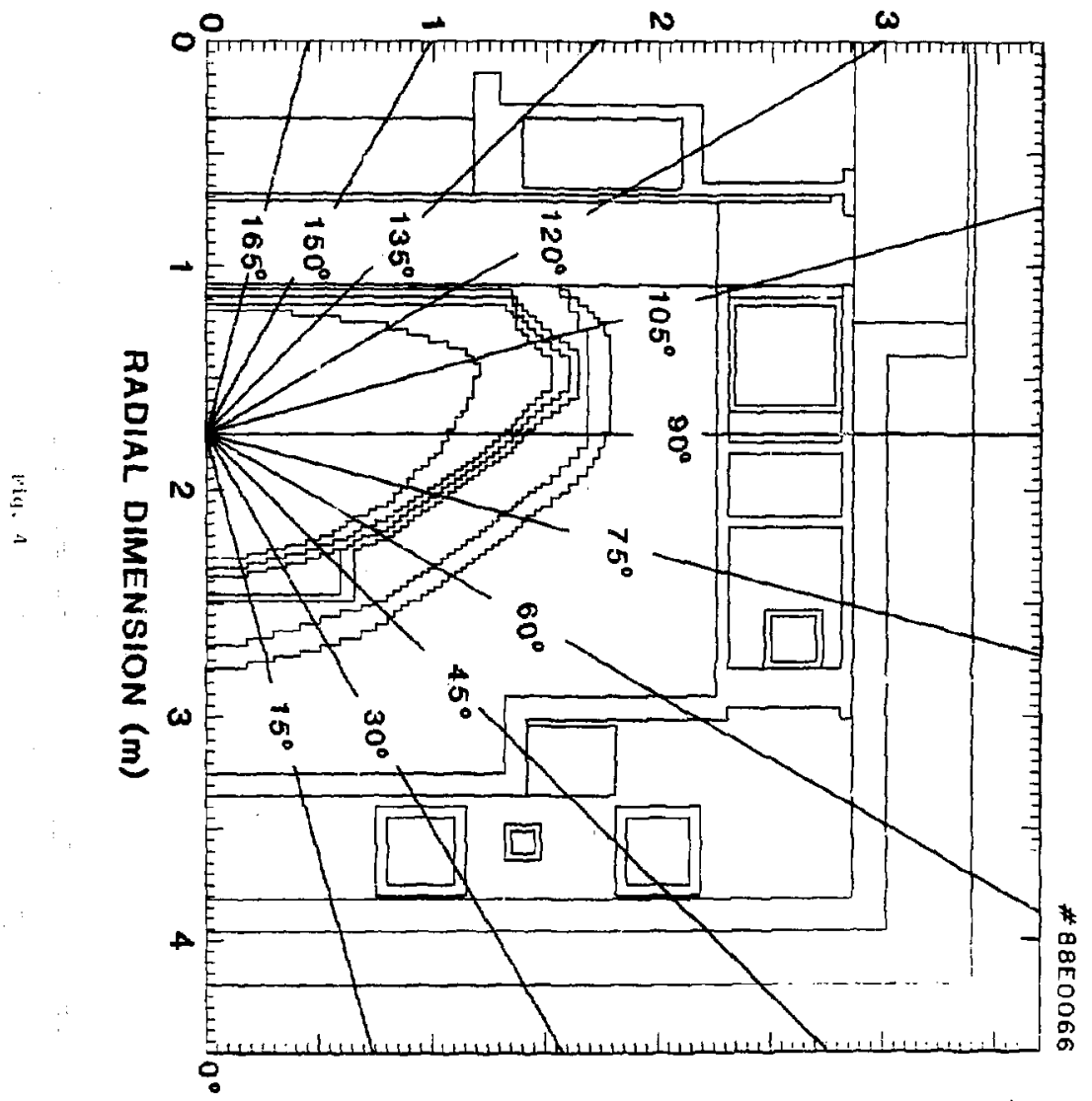




\section{RADIAL DIMENSION (m)}

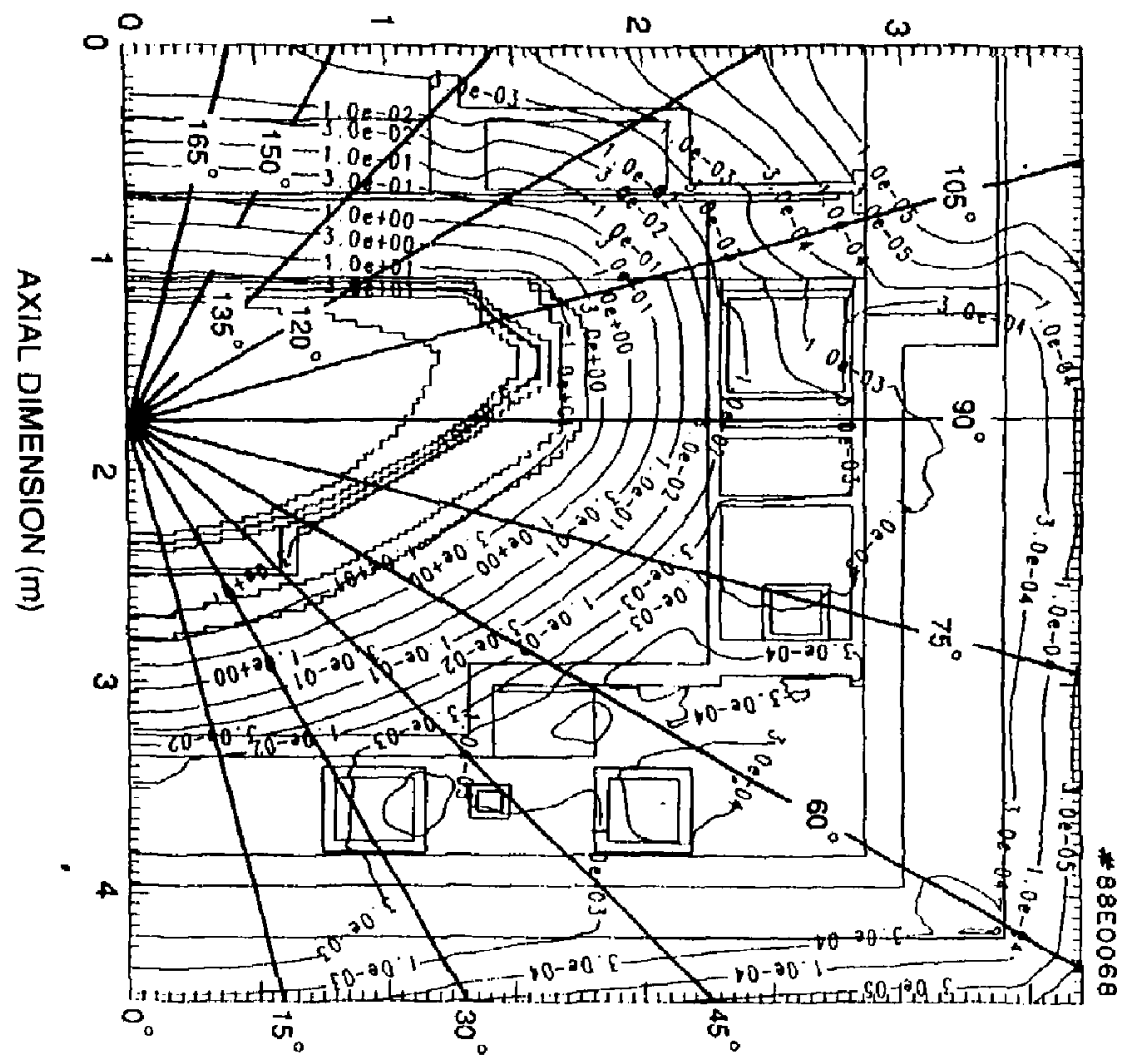




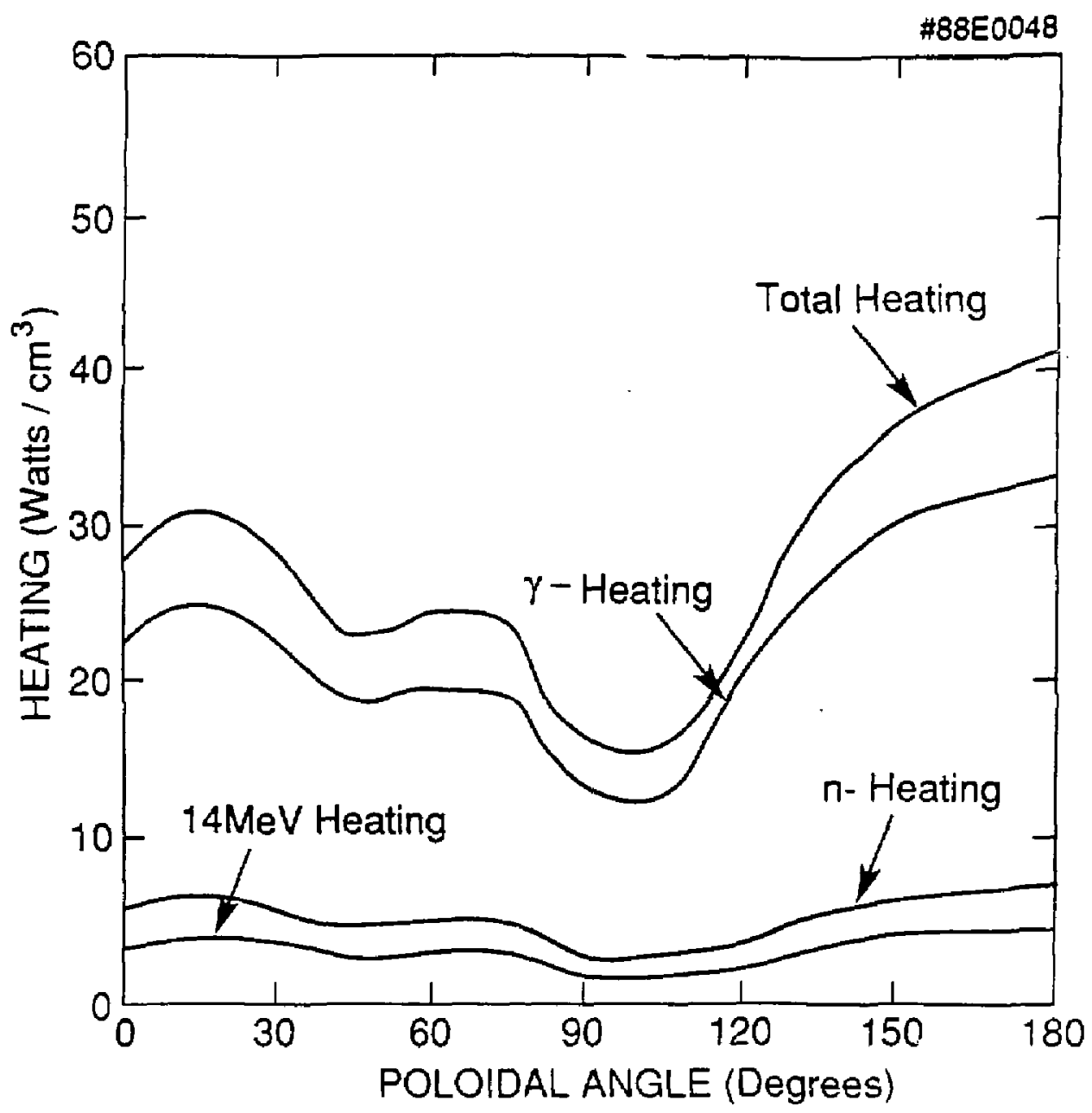

Eig. G(a) 


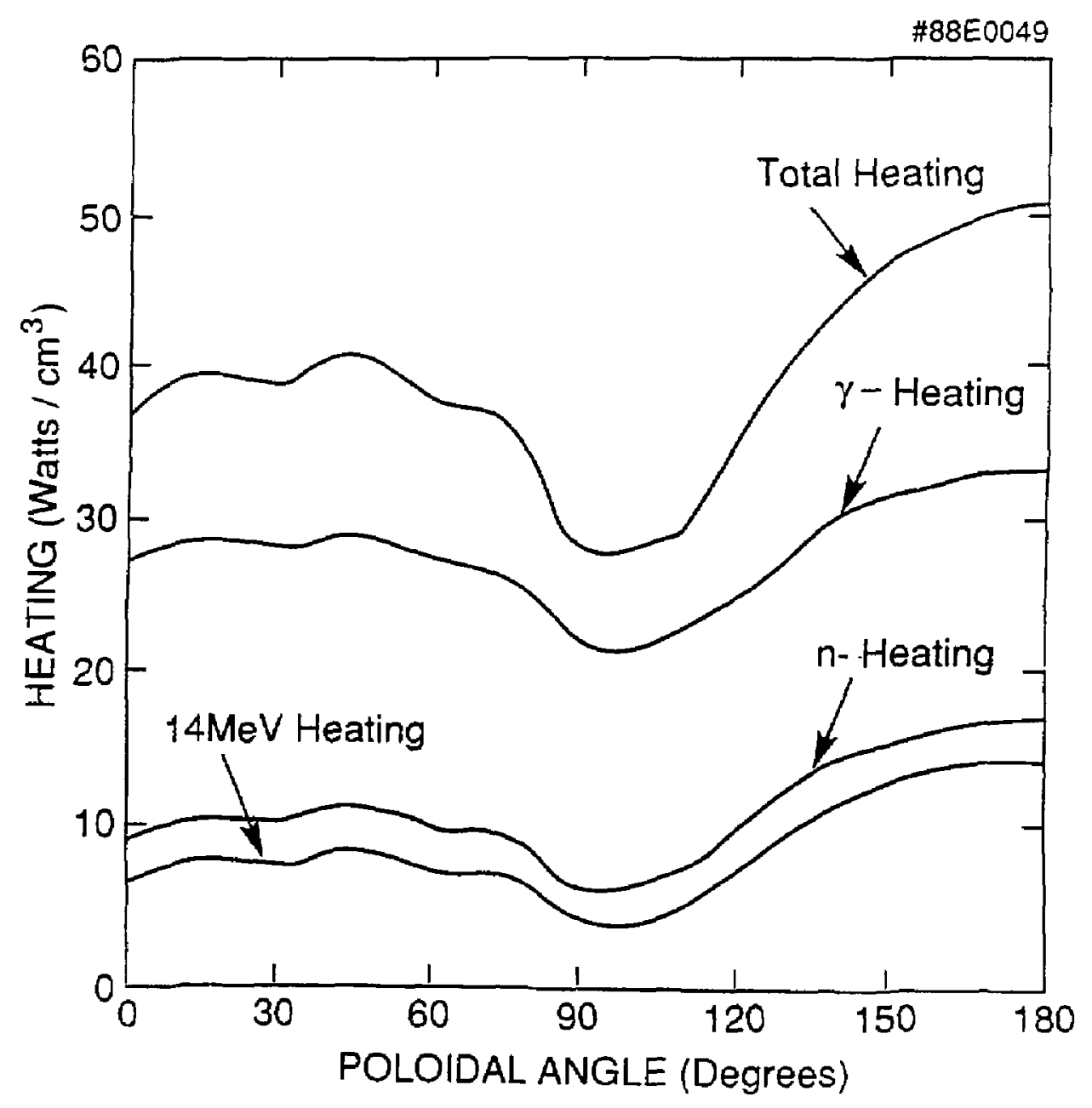

I. $6.6(b)$ 

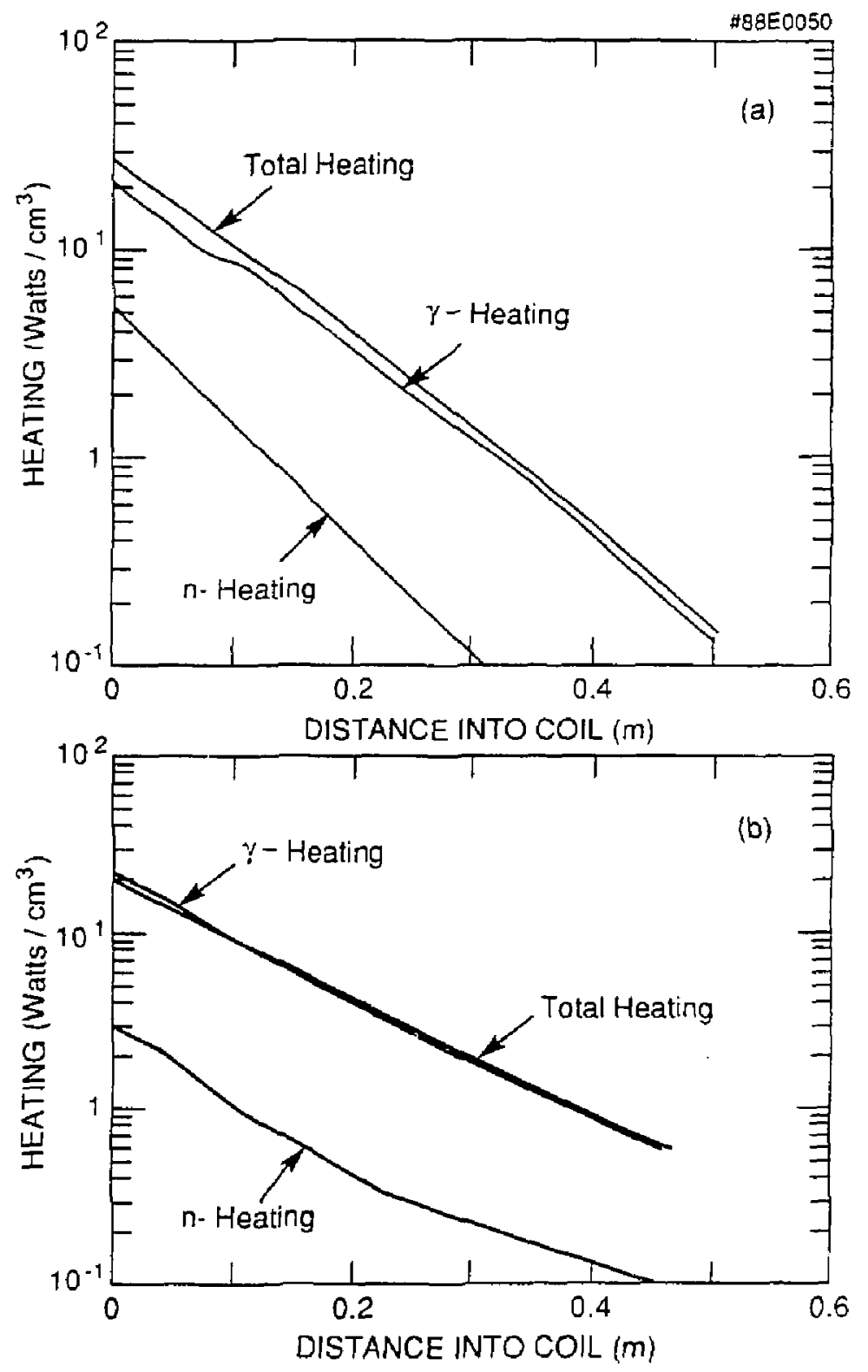

Eig. 7 


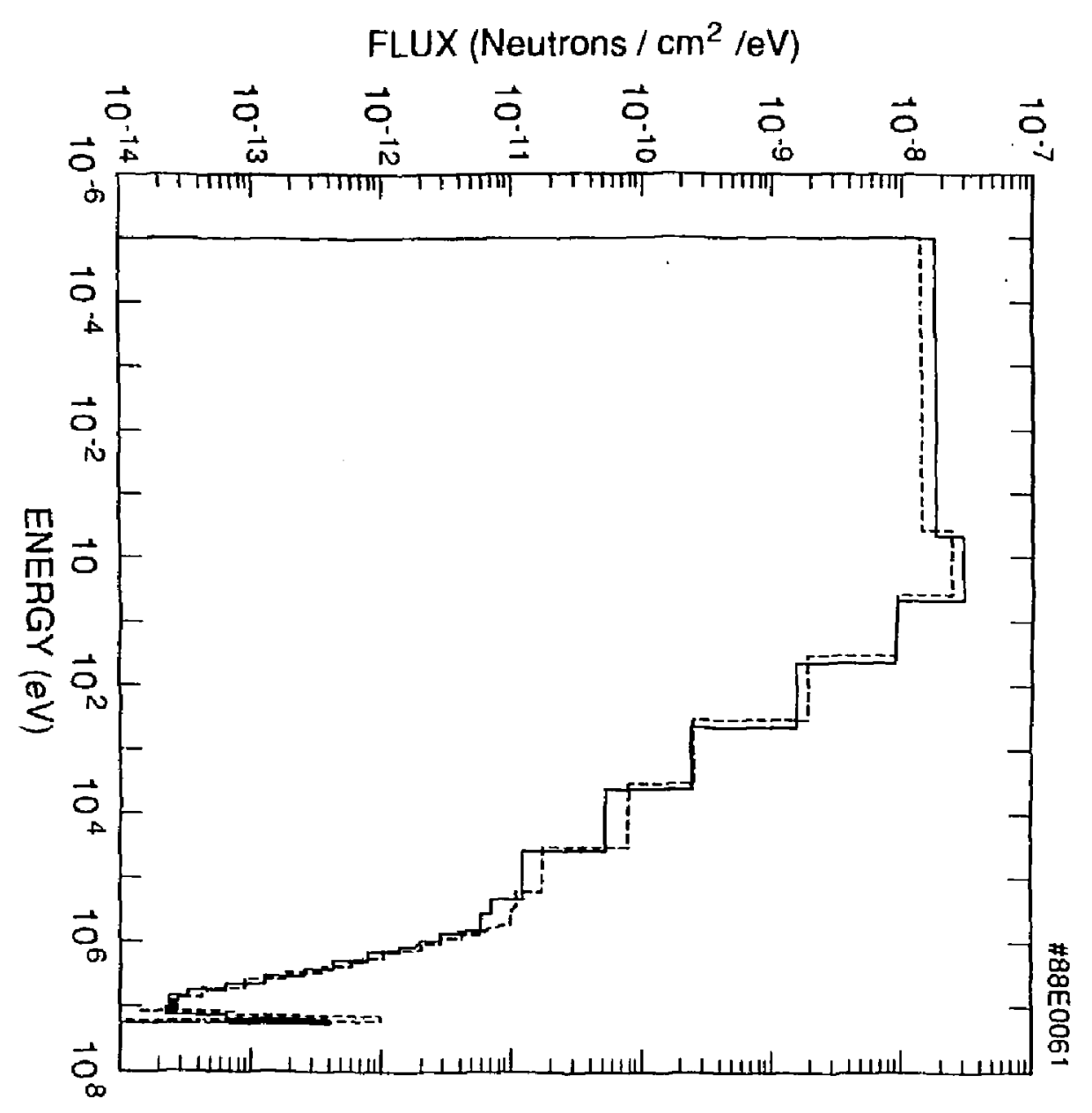




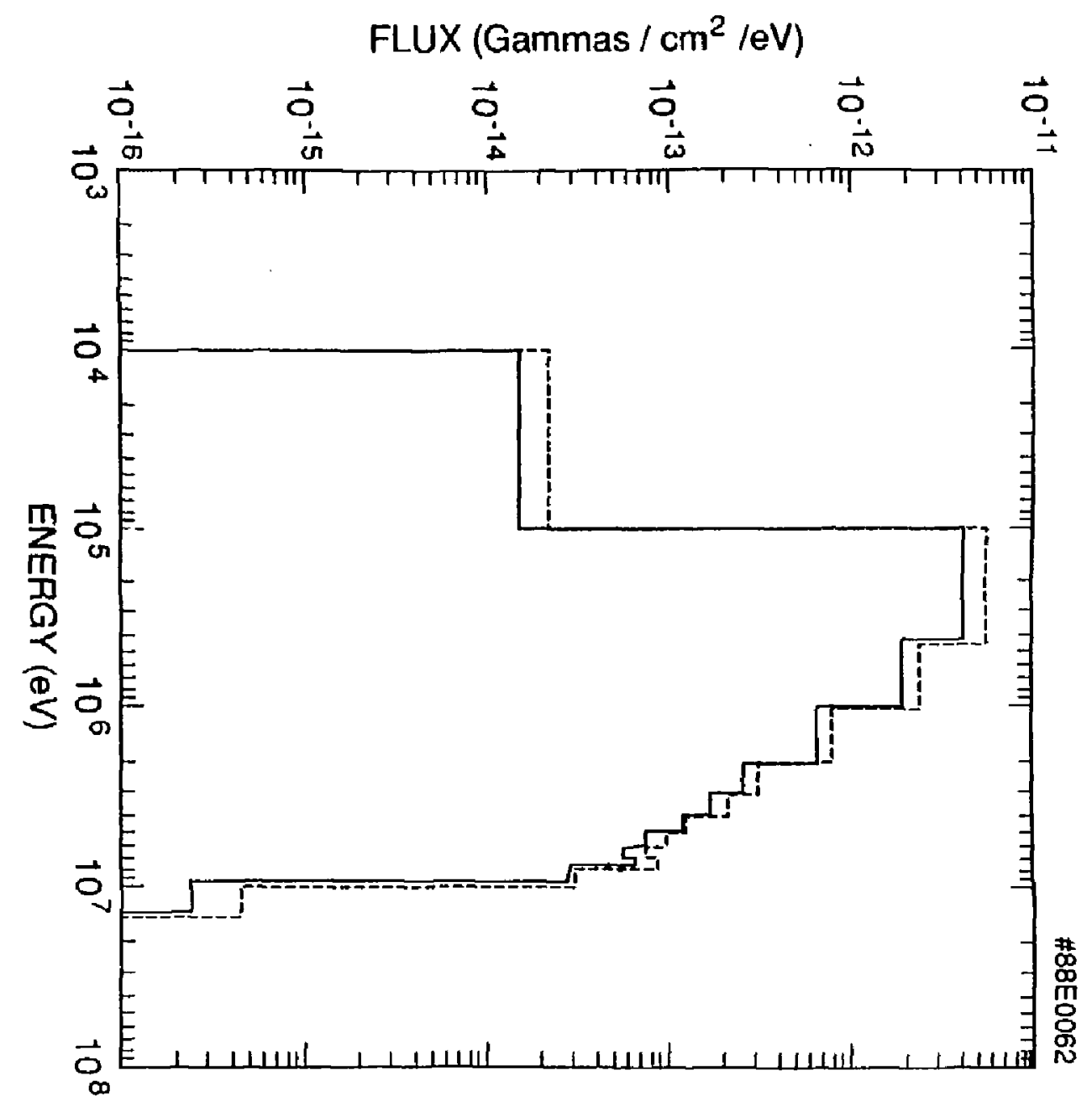




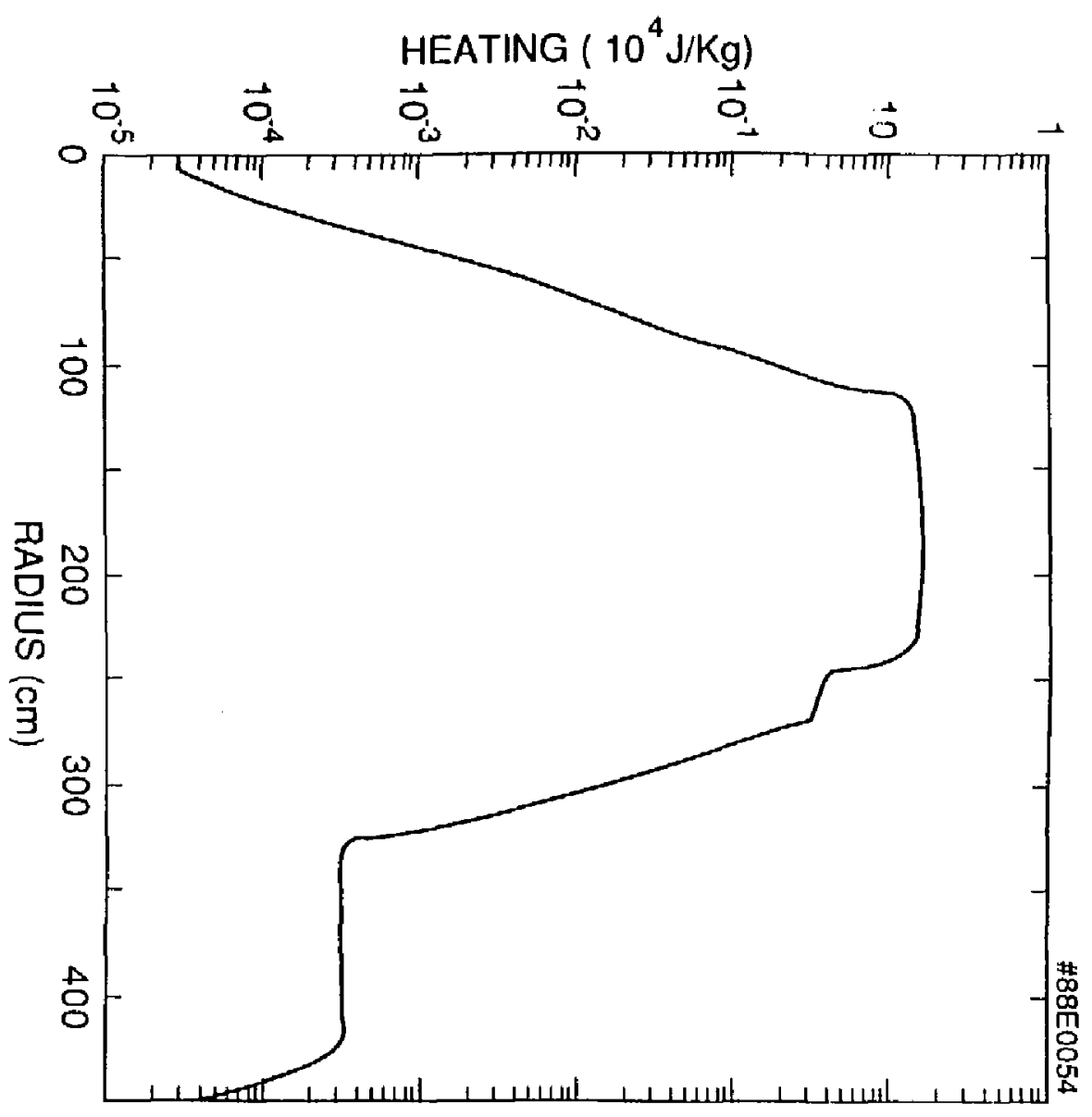



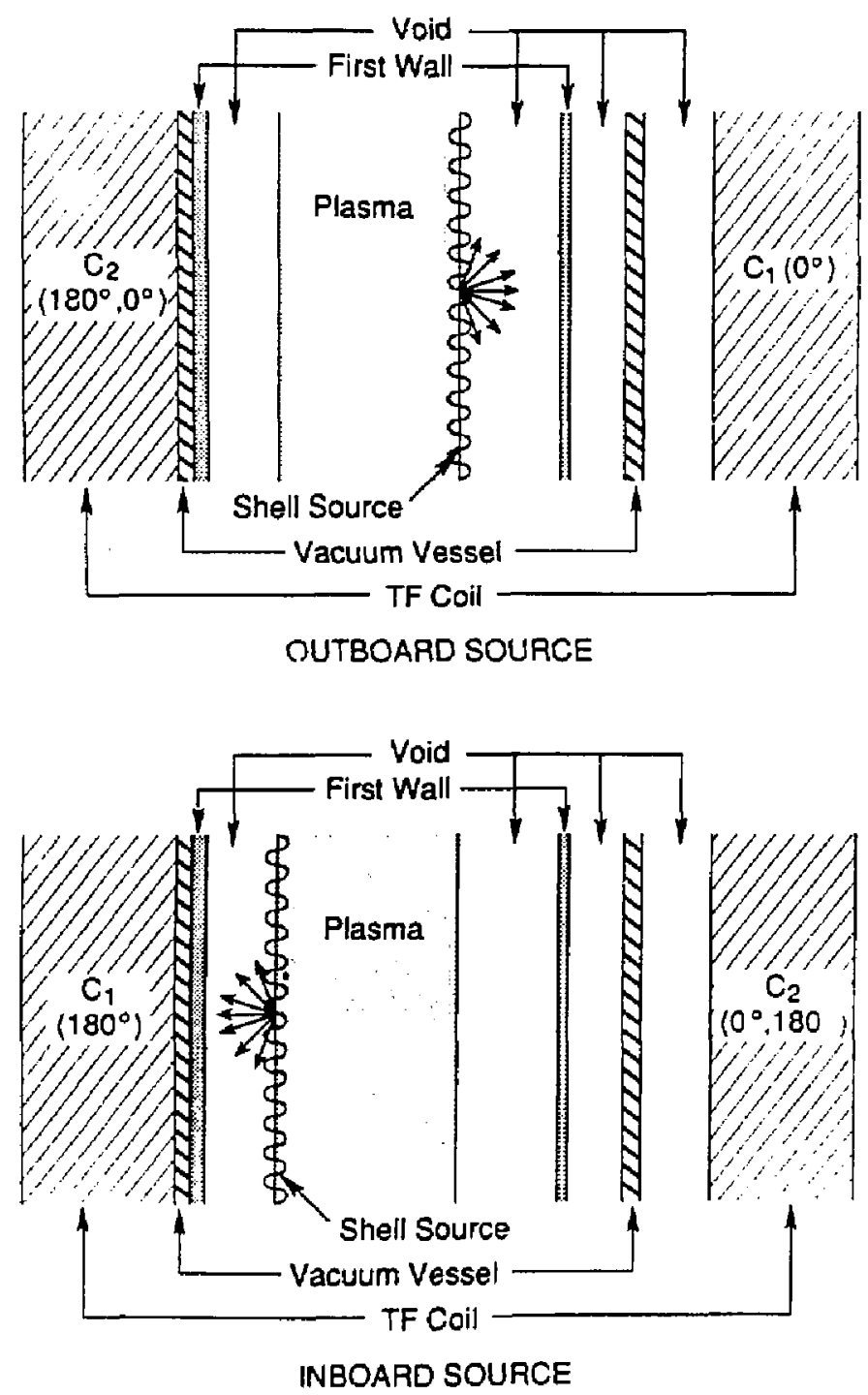

Fig. 10 
4 B86.0063

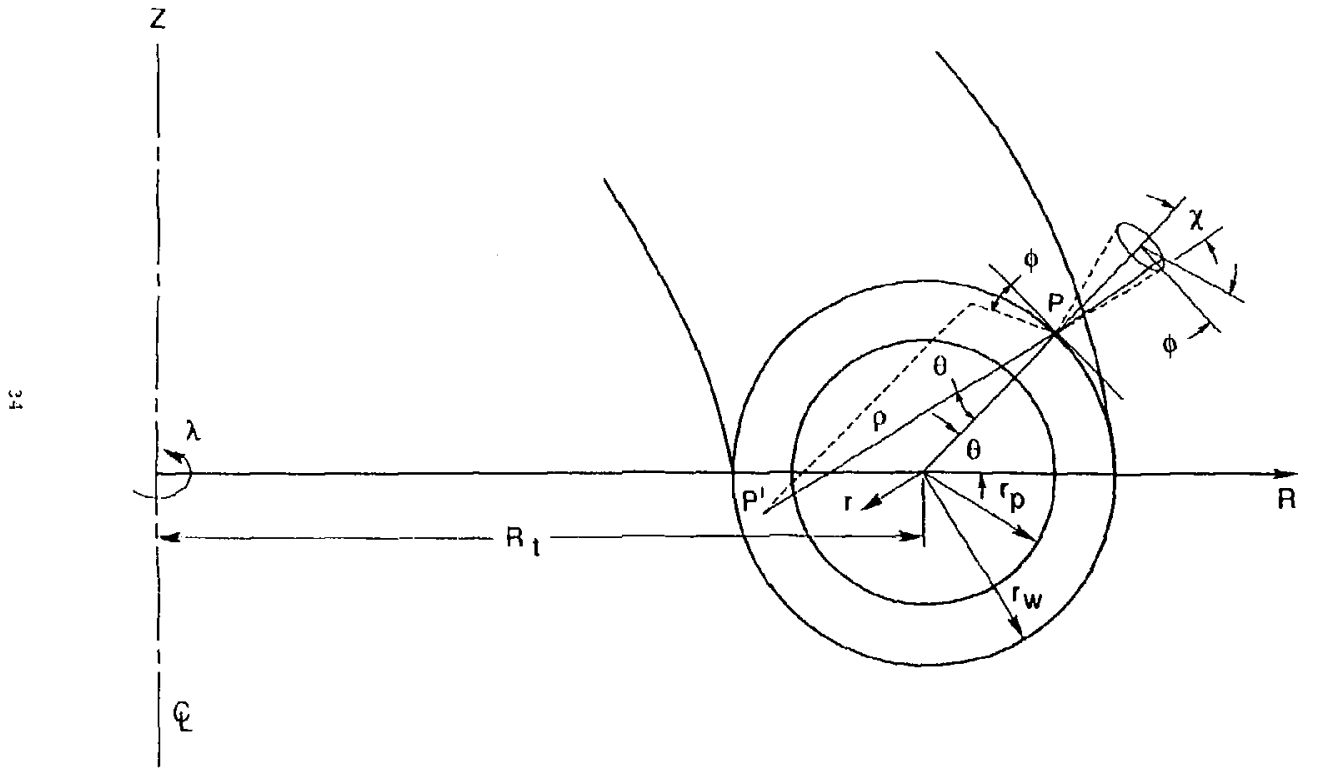




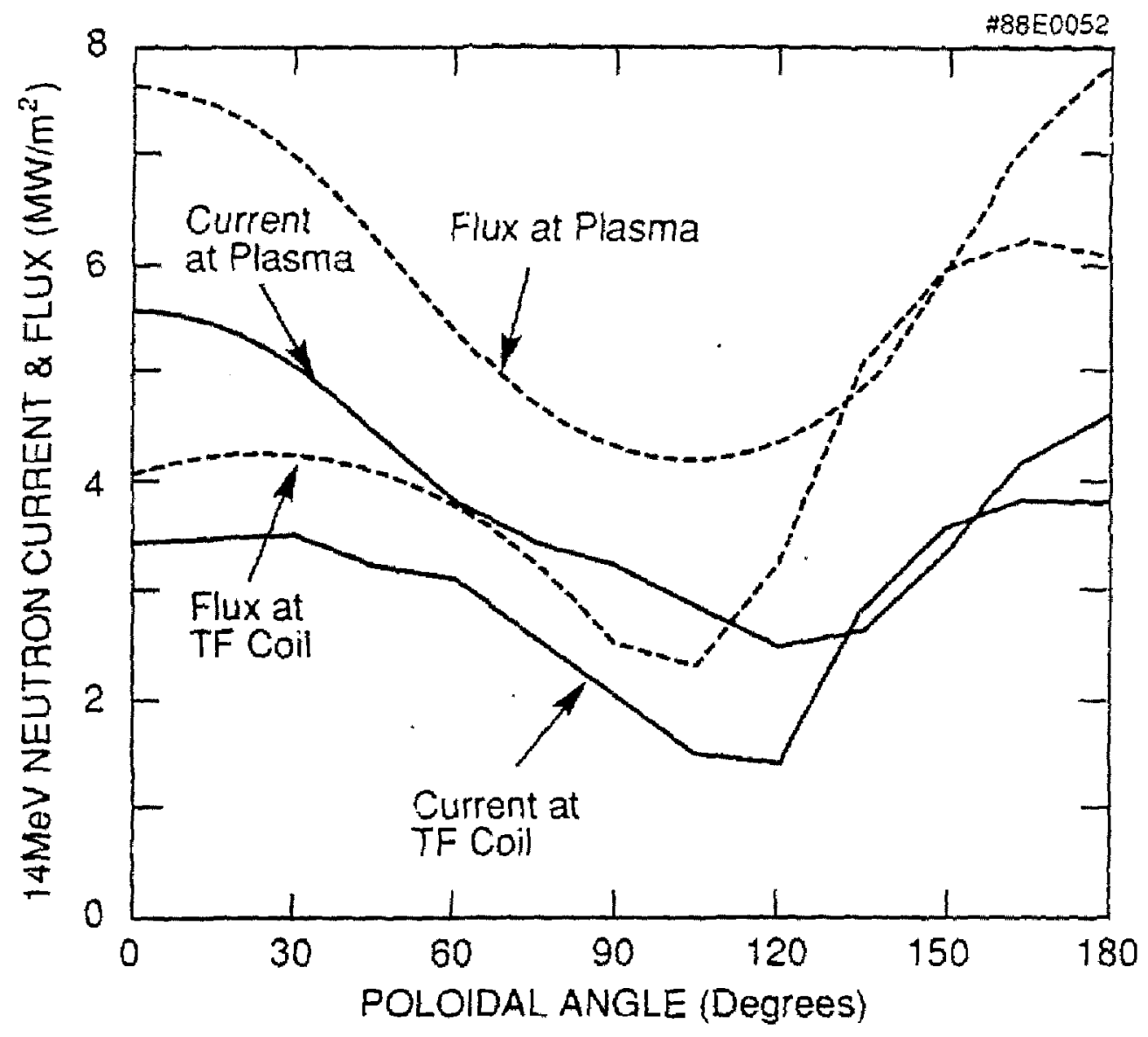

Fig. 12 


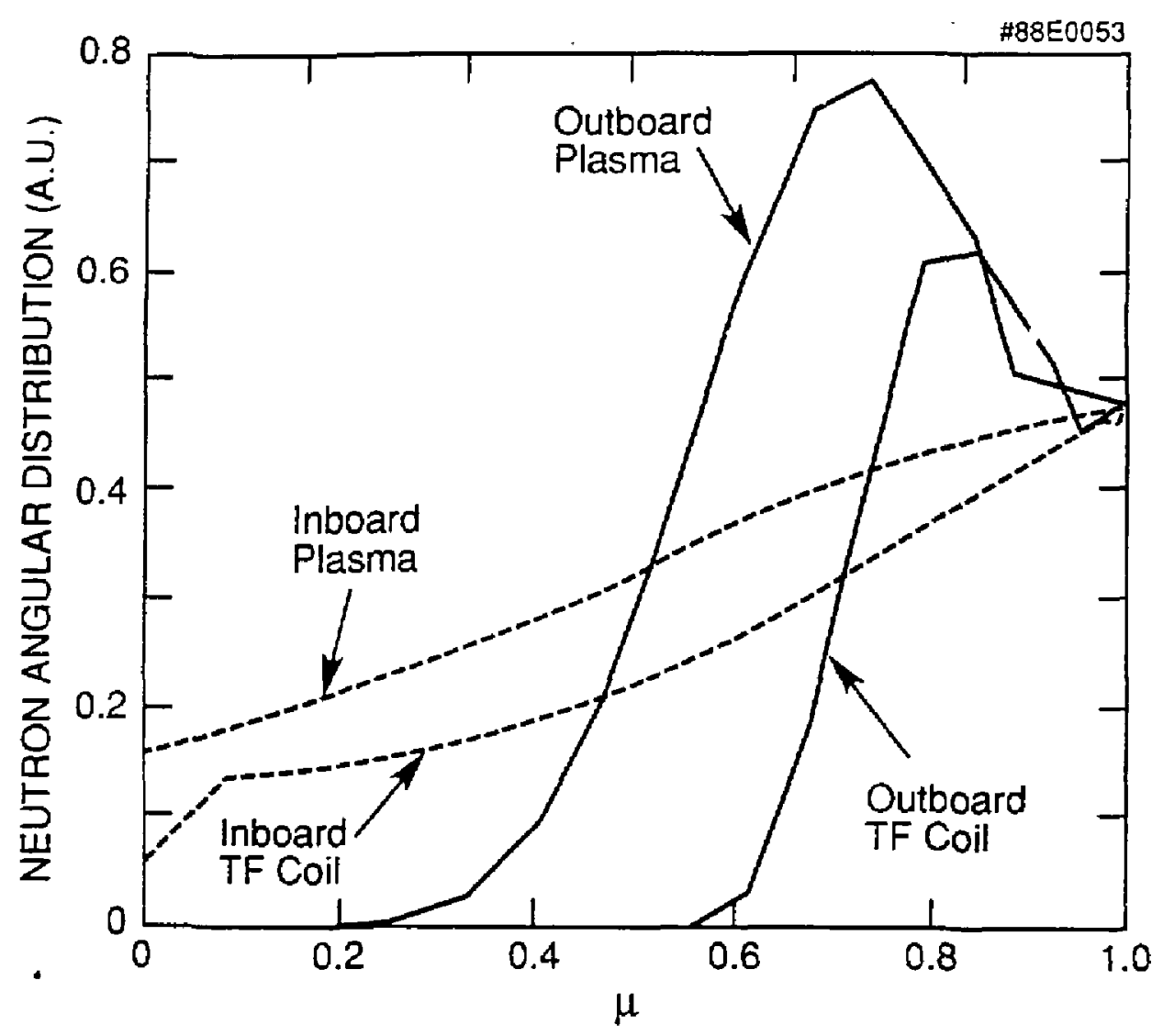

Eig. 13 

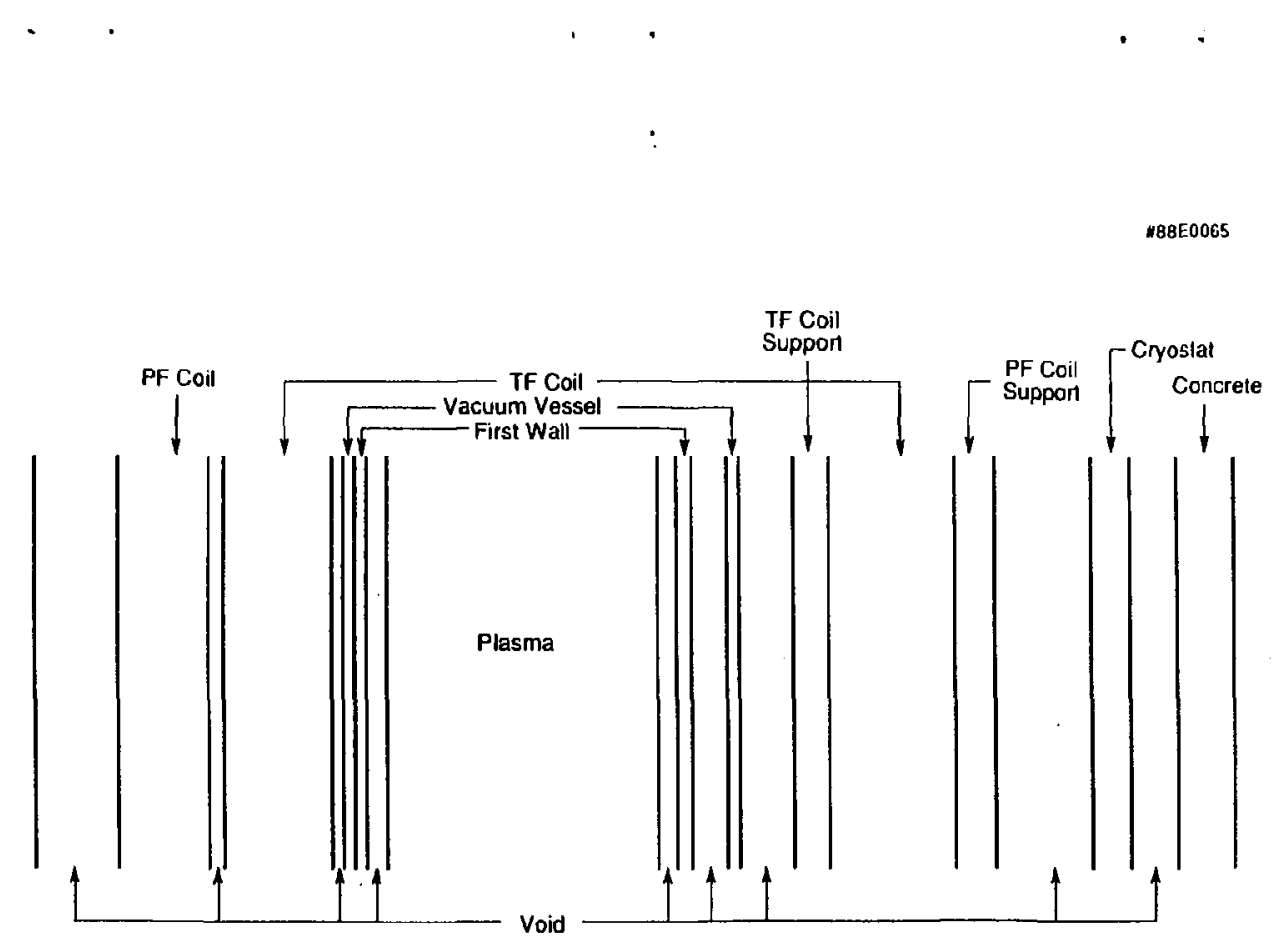

pirg. 14 


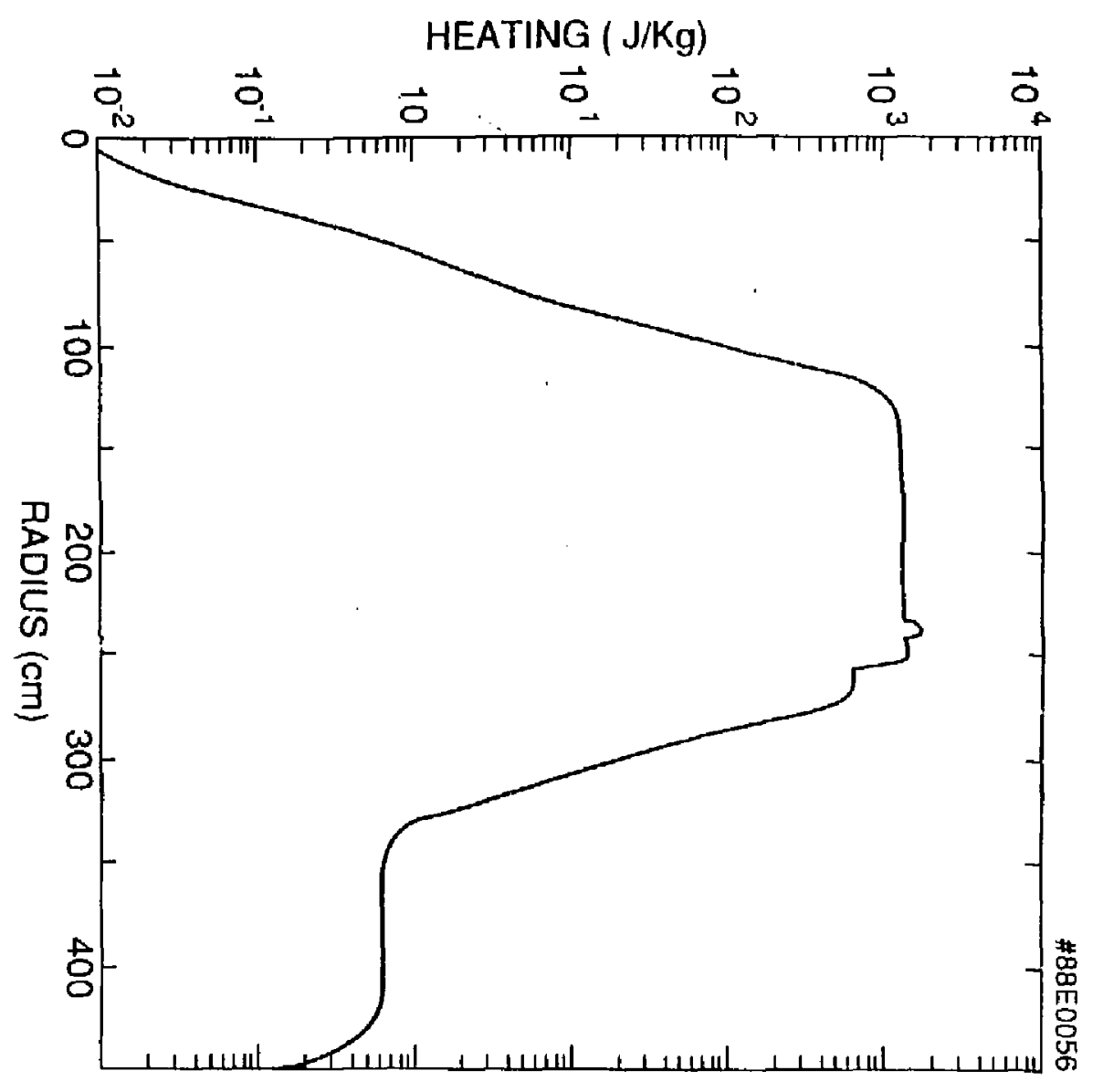




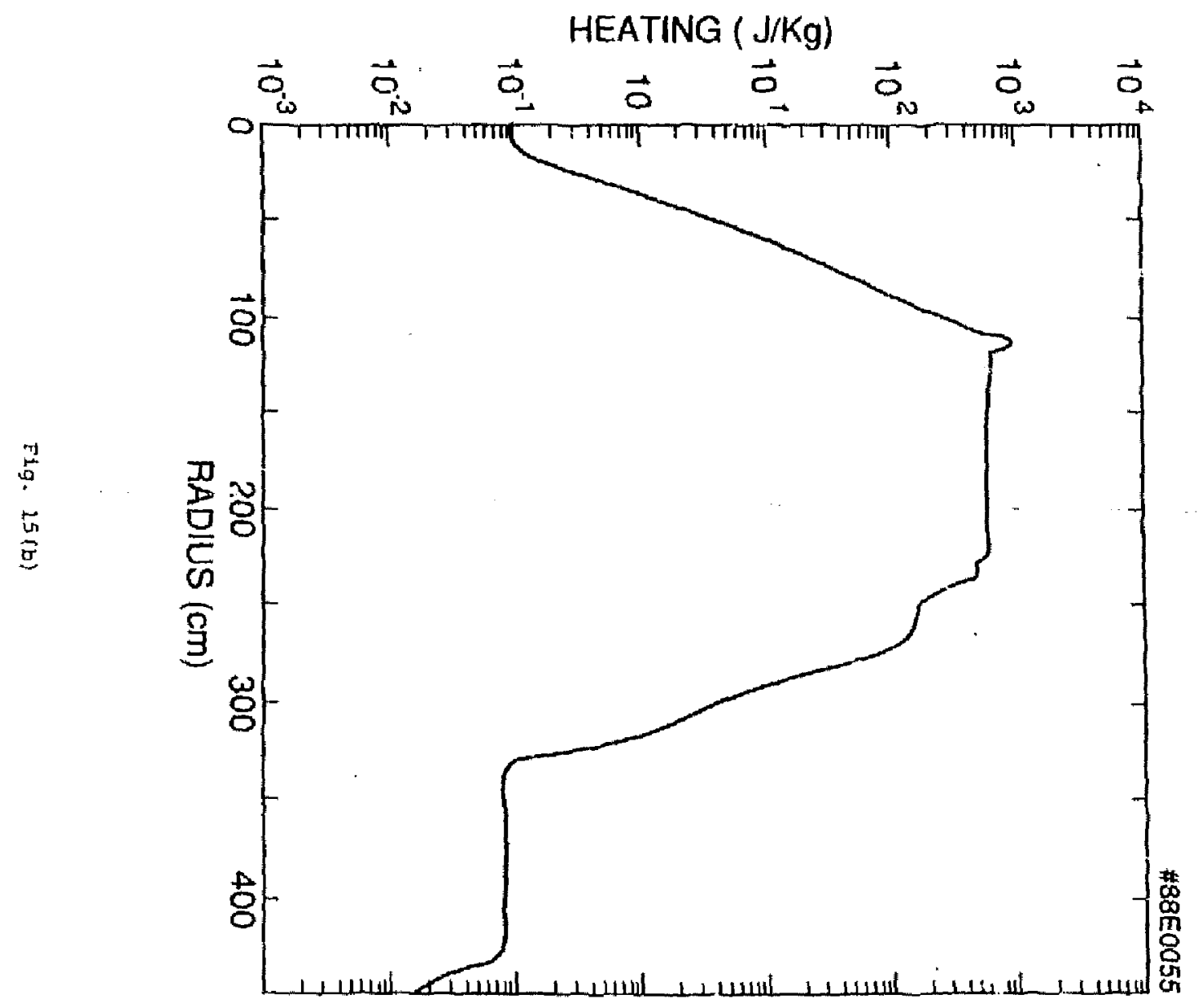




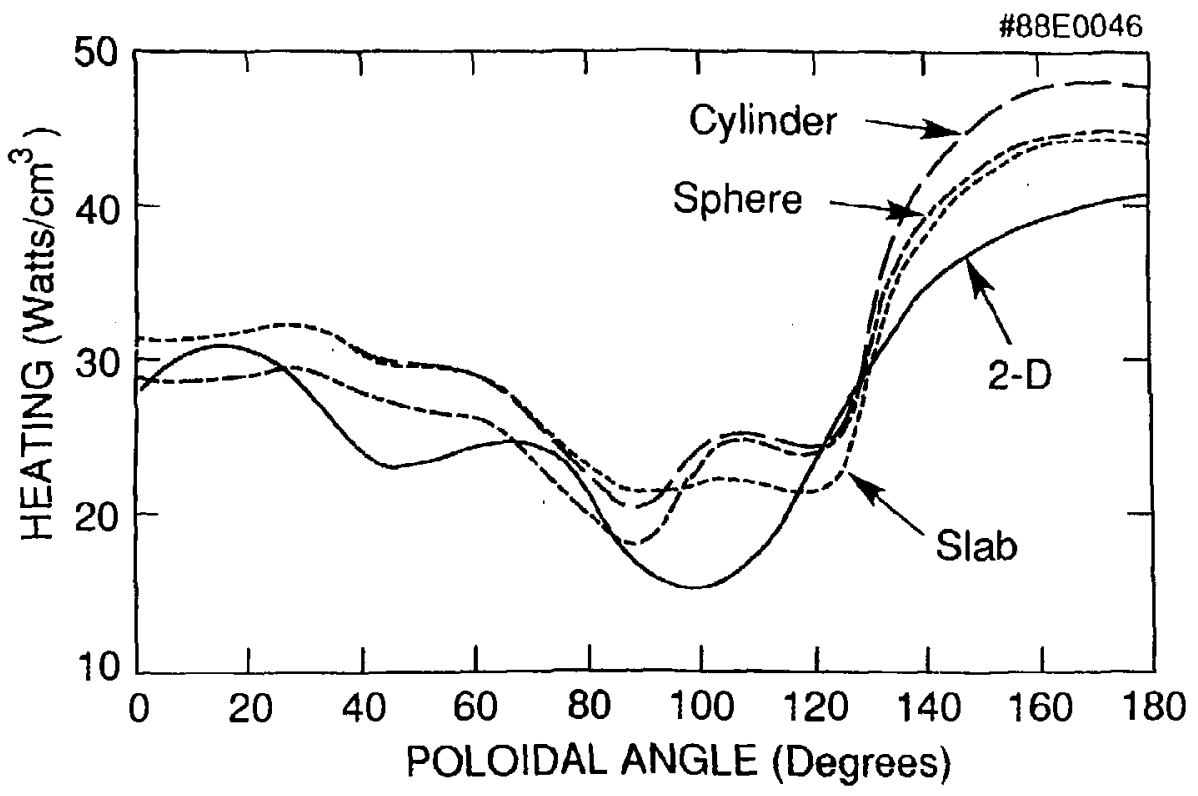




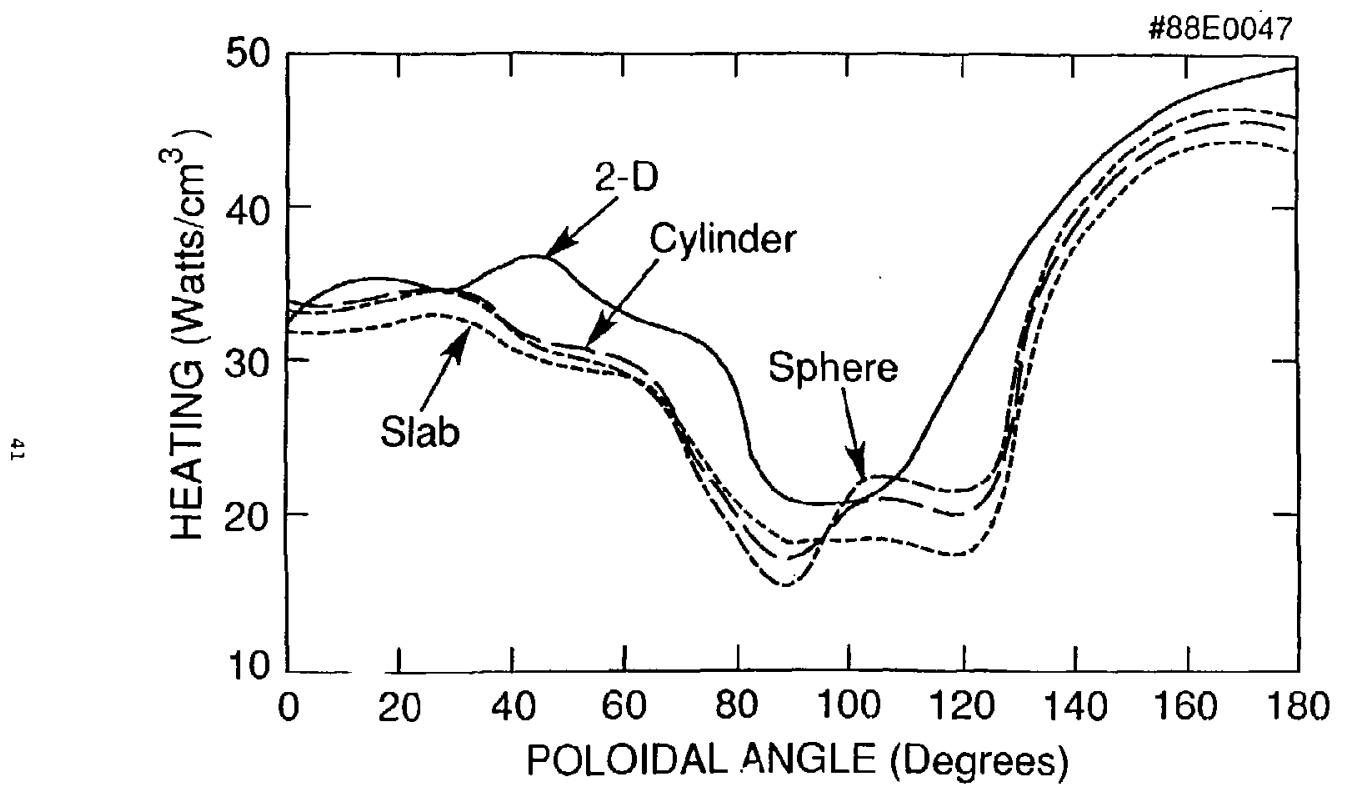




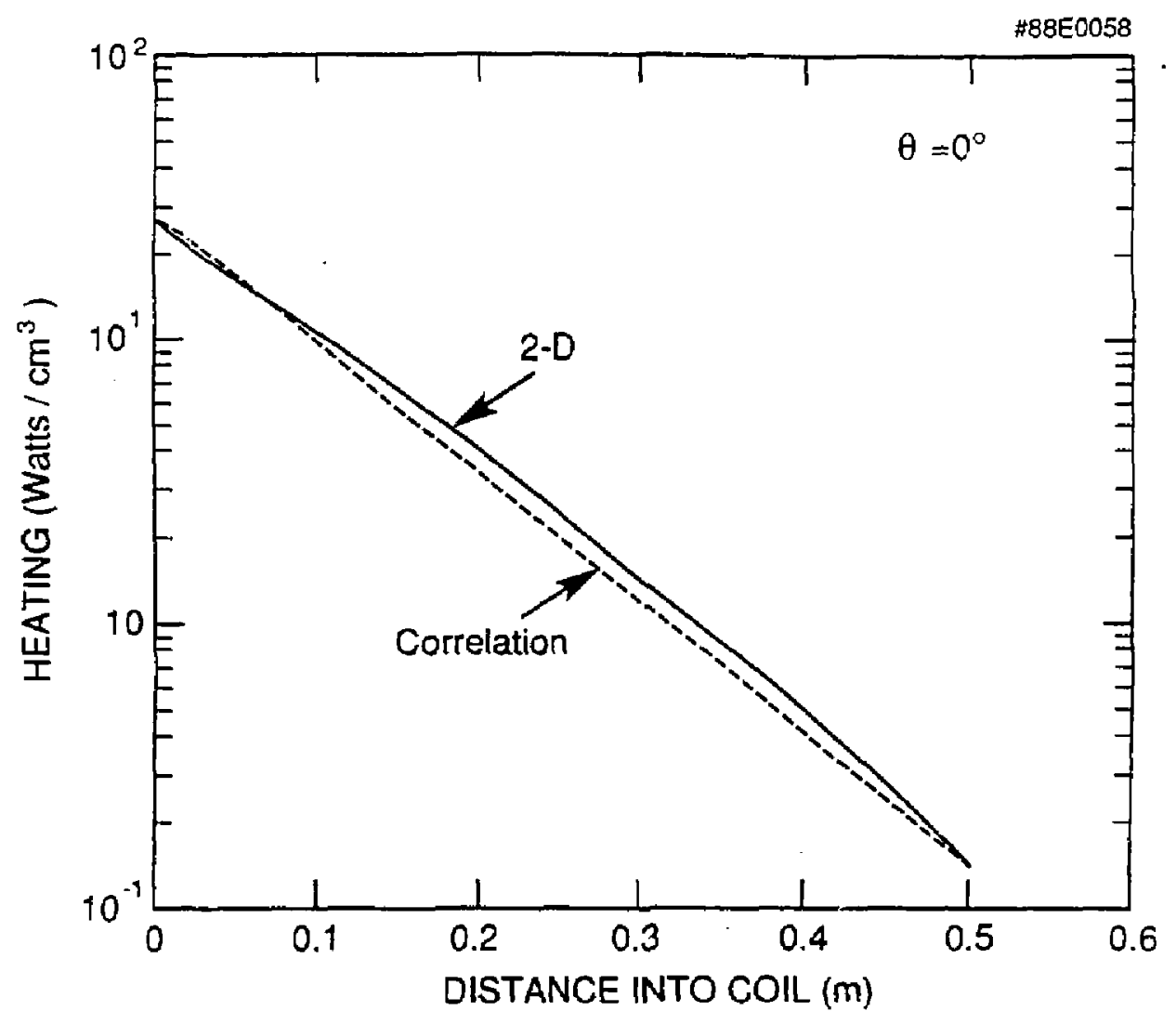

Fig. $17(a)$ 


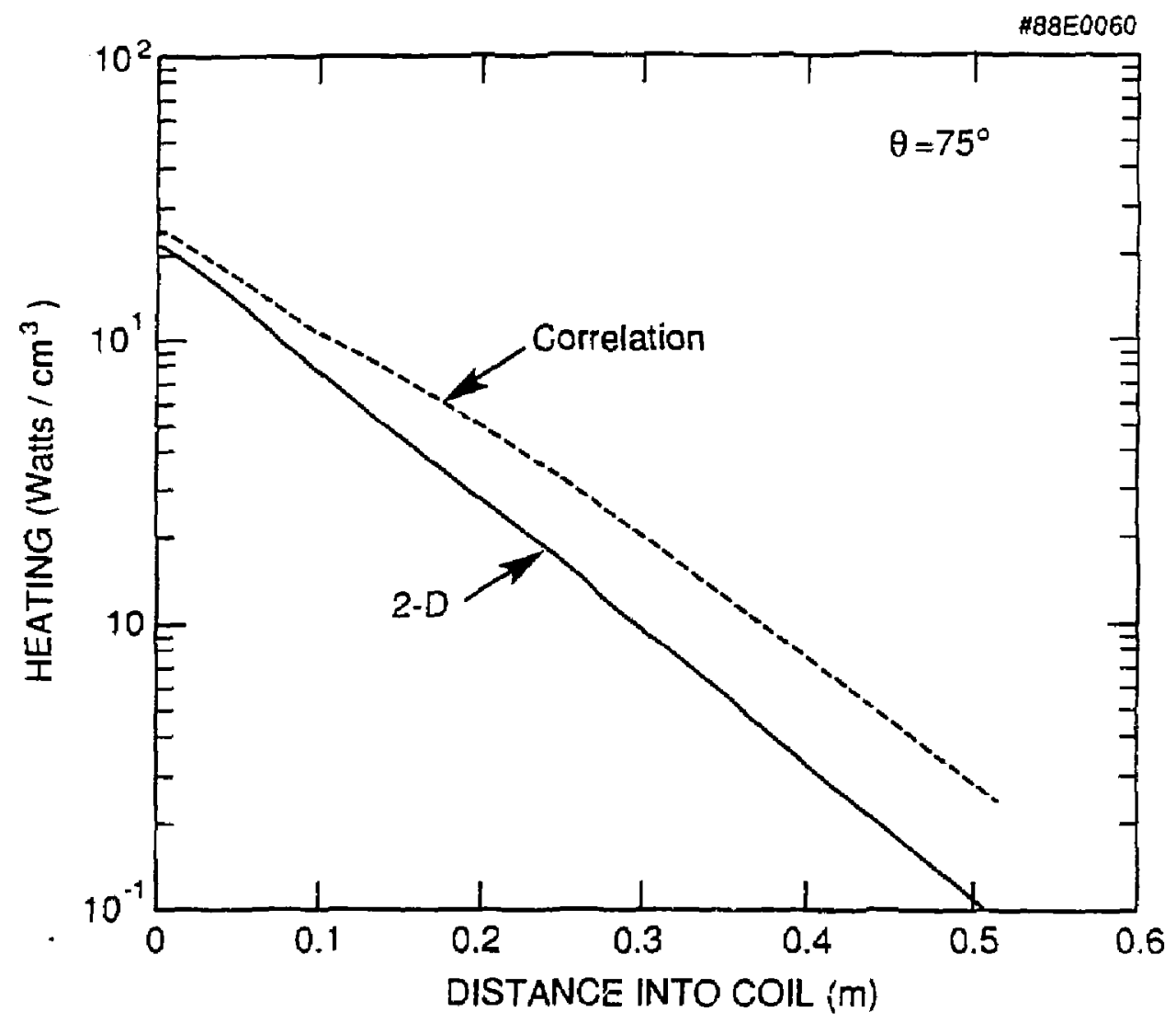

Fig. 17 (b) 


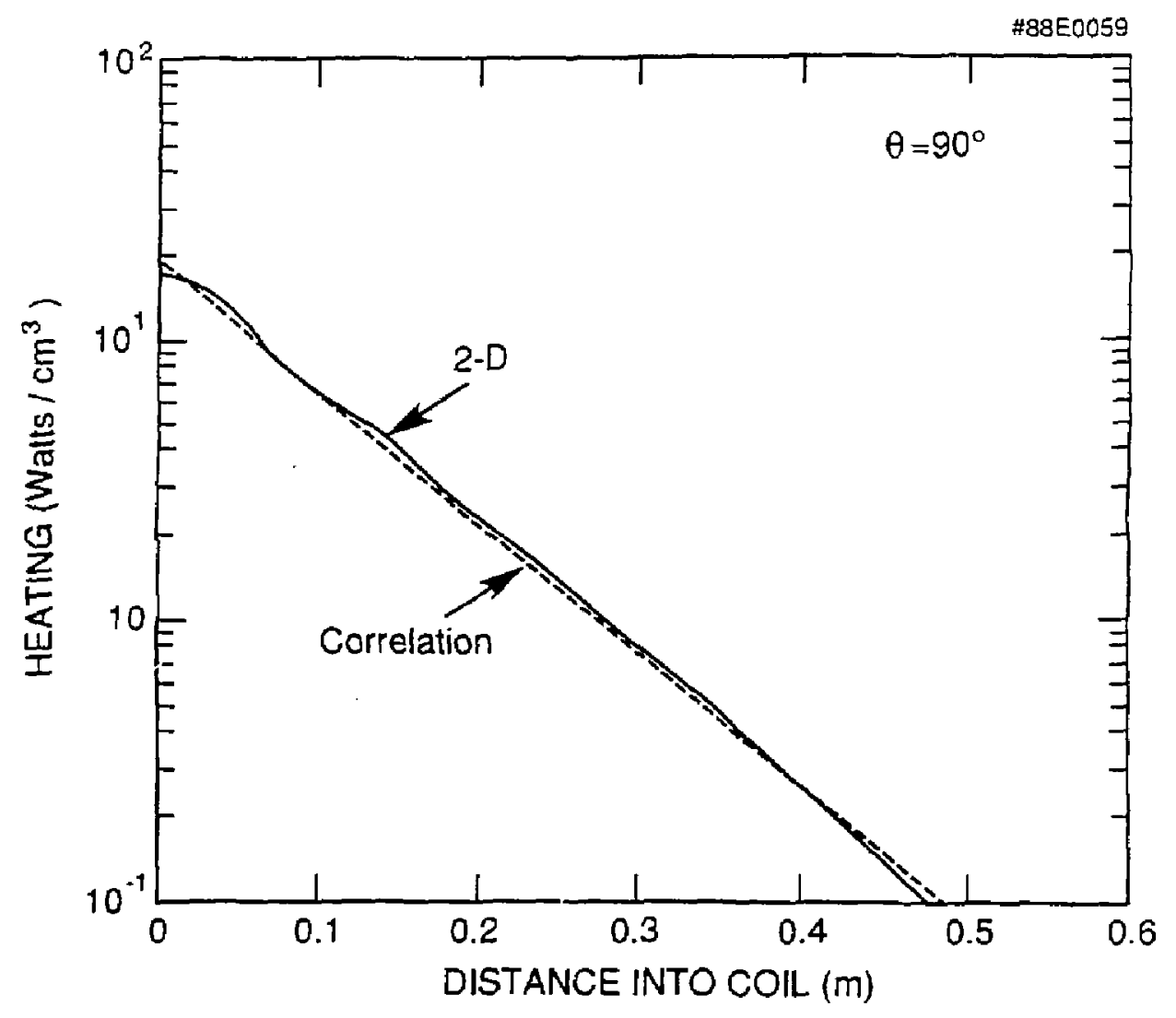

Fig. $17(c)$ 


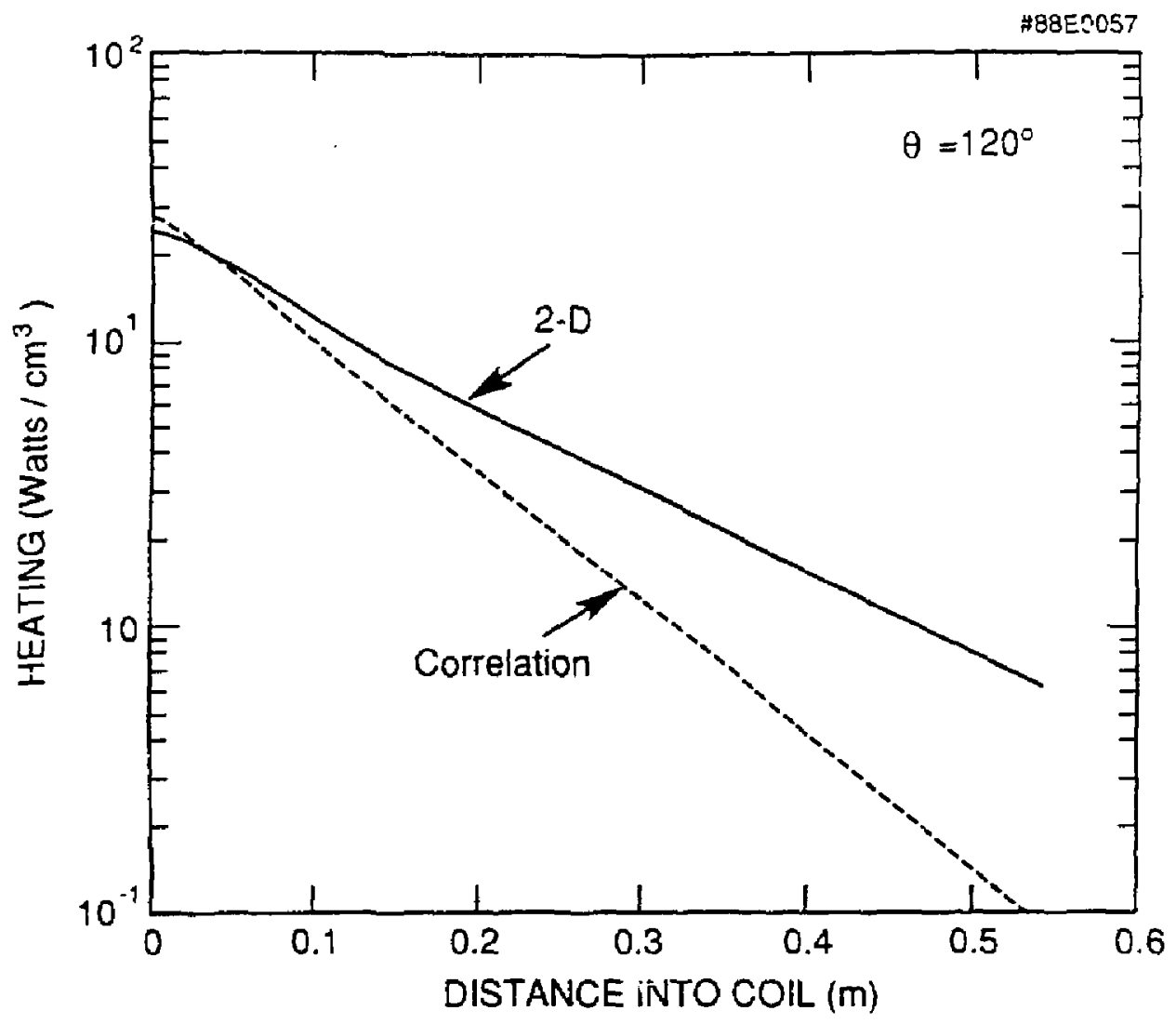

Fig, $I 7(d)$ 
Dr, Fiank J. Paoloni, Univ of Wollongong, AUSTRALIA

Prol. M.H. Bronnan, Univ 5yoney, AustRaLiA

Plasme Research Lab., Austrolian Mot. Univ., AlJSTRALIA

Prol. I,A, Jondes, Fl inders Univ.., Australlia

Prof. F, Cap, Inst Theo Phys, Austria

Prof. H. Heindler, institut fur Theoretische Physik, AUSTRIA

M. Goossens, Astronomiseh Instituut, BELGIUM

Ecale Royale Militaire, Lab de Phys Plasmas, BeLgilum

Comission-Eurogean, $0 g-x \| I$ fusion Prog, BELGIUM

Prof. R. Boucique, Laboratorium voor Natuurkunde, BELGIUM

Dr. P.H. Sakanaka, Instituto Fisica, BRAZlL

Instituto De Pasquisas Espociasi-IRPE, BRazlL

Docuents Offica. Atomic Energy of Canada Limited, Camad

Dr. M.P. Bochynaki, MPQ Jechnologias, Ine., Cawnes

Dr. M.M. Skarsgard, University of Sagkatehamen, CMulan

Dr. H. Garnard, University of British Columbia, CANAOA

Prof. J. Tuichwann, Univ. of Montraal, Cakwa

Prof. S.R. Sruenivasan, Univarsity of Calgary, Camada

Prof. Tudor W. Johnston, IMAS-Energla, CAMDA

Dr. C.R. Jamas, Univ. of Alberta, Caruan

Dr. Pater Lukee, Komenskeho Univ, CZECHOSLOUAKIA

The Librarian, Culha laborstory, ENGLAND

The Librarian, Ruthertord ADpletan Laboratory, ENGLAND

Mrs. S.A. Hutehinson, JET Library, ENGLANO

C. Mouttet, Lab. de Physiqua des Milieux lon isés. France

1. Roder, CEN/CADARACHE - Bat 506, FRANCE

Uni,. of loennins. Library of Physies Dept. GREECE

Dr. Tom Mul, Acadeay Bibliograph ic Ser., Hons kOnG

Preprint Library. Hungerion Acadomy of Sciences, Hukenay

Dr. B. Dasgudta, Sana Inst of Nucl. Phys., INDIA

Dr. P. Kan. institute for Plasad Research, INDIA

Dr. Philip Rosensu, Israel Inst. Tech, ISRAEL

Librarian, Int"1 Ctr Theo Phys, ITALY

Praf. 6. Rostagni, Univ Ol Padova, ! TALY

Miss Clelia De Palo, Assoc EURATOA-ENEA, ITALY

Bibliotece, Instituto di fisica del Plasad, I TaLY

Dr. H. Yomato, Toshiba Res D Dev, JAPAN

Prot. :. Kawaheni, Atomic Enorgy Ras. Institute, JAPAH

Prof. Kyoji Nishikma, Univ of Hiroshima, JAPAN

Direc, Dept. Larga Tokanda Ras. JAERI, JAPAI

Prot. Satoshi Iton, Kyushu University, JAPAll

Rasearch Into Conter, Nagoya University, JAPAN

Prot. 5. Tanaks, Kyoto University, JAPAN

Library, Kyoto Univarsity, JAPAN

Prof. Hoouyuki Inoua, University of Tokyo, JAPAM

S. Mori, JAERI, JAPAN

Librarian, Korea Aduanead Energy Ras. Institute, KOREA

Prof. D.1. Thoi, Adv. Inst Sci \& Tach, KCPEA

Prof, a.s. Liley, University of Waikato, MEW ZEALAND

Institute of Plasan Physlcs, PECPIE'S REPUALIC OF CHIM

Libraridn, Institute of Phys., PEOPLE'S AEPUALIC OF CHIM

Library, Tsing Hud University, PEOPLE's AEPUBLIC G OHINA
2. Li, Southwest Inat. Physics, PEOPLE's REPUalic of CHINA Prot. J.A.C. Cabral, Inat Superior Tecnics, PoATugal

Dr. Octavian Petrus, AL I CUZA Univarsity, ACMANIA Dr. Johan da Villiers, fusion Studies, AEC, SO AfRICA Prot. M.A. Halloerg, University of Natal, SO AFRICA C.I.E.M.A.T., Fusion Div, Library, SPAIN Dr. Lennart Stentlo, University of UAEA, SWEDEN Library, Royal Inst Tech, SWEDEN

Prof. Hans Whihelmson, Chalmers Univ Tech, SWEDEN Contre Phys des Plasmas. Ecole Polytech Fud, SWI TZERLAND Bibliothenk, Fom-lnst Yoor Plosma-Fysica, THE NETHERLAHOS Dr. D.D. Ryutov, Siberian Aead Sef, USSR

Dr. G.A. Eliseev, Kurchatov Institute, USSR

Dr. V.A. Gluknikh, Inst Electrophrsical ADDaratus, USSR

Or. V.T. Tolow, Inst. Phys. Tech. USSR

Or. L.M. Kourizhnykh, Institute Gen. Physics, USSR Nucl a Rar Ras. Establishment. Julieh Ltd., W. GERuAnr Bibliothek, Inst. Fur Plasmatorschung, $W$. GeEaMAr Dr. K. Schindler, Ruhr Univers itat Bochue, W. GERaMANY ASDEX Reading Ru, IPP/Max-PIanck-Institut fur

Plasngohysik, W. GERHAlt

Librarian, Maxtilanck Institut, W, GEFo-ANY

Prof. R,K, Janev, Inst Phys, Yucosiavia 